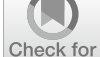

updates

Cite as

Nano-Micro Lett.

(2021) 13:56

Received: 18 October 2020

Accepted: 30 November 2020

Published online: 12 January 2021

(C) The Author(s) 2021

\section{A Review on Metal-Organic Framework-Derived Porous Carbon-Based Novel Microwave Absorption Materials}

\author{
Zhiwei Zhang ${ }^{1}$, Zhihao Cai ${ }^{1}$, Ziyuan Wang ${ }^{1}$, Yaling Peng ${ }^{1}$, Lun Xia ${ }^{1}$, Suping $\mathrm{Ma}^{1}$, \\ Zhanzhao Yin ${ }^{1}$, Yi Huang ${ }^{1}$
}

\title{
HIGHLIGHTS
}

- The theoretical knowledge in the field of microwave absorption is summarized in detail.

- The recent progress of metal-organic frameworks-derived porous carbon-based nanocomposites as microwave absorption materials is reviewed.

ABSTRACT The development of microwave absorption materials (MAMs) is a considerable important topic because our living space is crowed with electromagnetic wave which threatens human's health. And MAMs are also used in radar stealth for protecting the weapons from being detected. Many nanomaterials were studied as MAMs, but not all of them have the satisfactory performance. Recently, metal-organic frameworks (MOFs) have attracted tremendous attention owing to their tunable chemical struc-

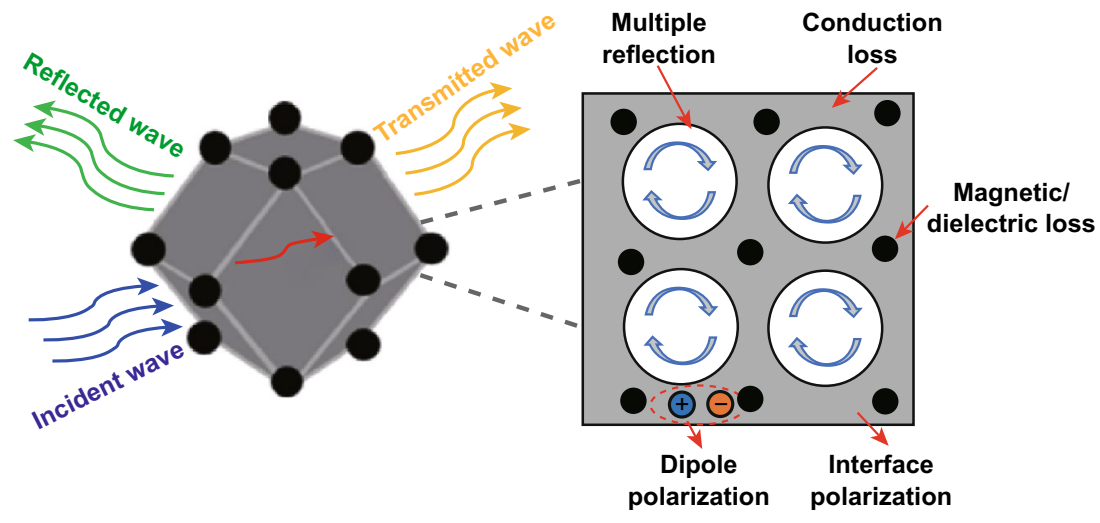
tures, diverse properties, large specific surface area and uniform pore distribution. MOF can transform to porous carbon (PC) which is decorated with metal species at appropriate pyrolysis temperature. However, the loss mechanism of pure MOF-derived PC is often relatively simple. In order to further improve the MA performance, the MOFs coupled with other loss materials are a widely studied method. In this review, we summarize the theories of MA, the progress of different MOF-derived PC-based MAMs, tunable chemical structures incorporated with dielectric loss or magnetic loss materials. The different MA performance and mechanisms are discussed in detail. Finally, the shortcomings, challenges and perspectives of MOF-derived PC-based MAMs are also presented. We hope this review could provide a new insight to design and fabricate MOF-derived PC-based MAMs with better fundamental understanding and practical application.

KEYWORDS Metal-organic frameworks; Porous carbon; Microwave absorption material; Reflection loss; Effective absorption bandwidth

Yi Huang, yihuang@nankai.edu.cn

National Institute for Advanced Materials Tianjin Key Laboratory of Metal and Molecule Based Material Chemistry, Key Laboratory of Functional Polymer Materials, Collaborative Innovation Center of Chemical Science and Engineering (Tianjin), School of Materials Science and Engineering, Nankai University, Tianjin 300350, People's Republic of China 


\section{Introduction}

The rapid development of science and technology made many kinds of electronic devices become irreplaceable role in human's daily life [1-7]. However, the electronic devices make the space rife with electromagnetic waves (EMWs) [8-14]. The EMWs become a new and more hazardous source of pollution as water, air and noise pollution [15-17]. On the one hand, the undesirable EMW may make strong interference to the nearby instruments, causing their malfunctioning and signal interruption. On the other hand, EMW may harm human's health which cause some disease such as cancer and endocrine disorder [18, 19]. Besides, plants can be inactive, variation and even die with the strong EMW radiation [20, 21]. It is urgently need for human to solve the problem of EMW pollution, while in the field of military, many advanced weapons such as warcraft are the key target of the enemy. EMW stealth technology of military equipment is a crucial solution to evade detection and attack. Coating of MAMs on military equipment is an effective anti-detection method [22]. Therefore, the exploration of high-performance MAMs is of great significance in both civil and military fields.

Recently, MAMs have received much attention because they have the ability to attenuate EMW. They can convert EMW into thermal energy or other forms of energy to dissipate [23, 24]. The ideal MAMs are often multiple loss mechanisms and they required to have lightweight, thin thickness, wide absorption bandwidth and strong absorption characteristics $[25,26]$.

Metal-organic frameworks (MOFs) are a kind of crystalline porous material with periodic network structure, which is composed of inorganic metal center (metal ion or metal cluster) and organic ligand connected by selfassembly [27-30]. Due to large amounts of organic ligands that could be used, MOFs have various of compositions and structures. As we know, more than 20,000 MOFs have been reported so far [31, 32]. MOFs have attracted lots of research interest due to their performance diversity, which are potential to extensive uses in many fields, such as electrochemical energy storage [33, 34], catalysis [35, 36], purification [37, 38] and sensing [39, 40]. Moreover, with MOFs as the precursor, carbon and metal-based compounds can be generated in situ by high-temperature pyrolysis in an inert atmosphere [28, 41, 42]. Fortunately, the morphologies of MOFs are still well preserved after pyrolysis [43, 44]. The MOF-derived PC nanocomposites also possess the desirable properties from MOFs [45] such as their tunable chemical structures, large specific surface area, uniform pore distribution, diverse morphology and chemical stability, which enable MOF-derived PC to be an ideal candidate for MA.

MOF-derived PC-based nanocomposites have been widely studied in the field of MAMs, but the attenuation mechanism may be relatively simple. In order to improve the attenuation performance, they usually coupled with other lossy materials. Based on the above views, how to design and prepare MOF-derived PC-based MAMs is now a hot research topic [46, 47]. In this review, we summarize the recent progress of several MOF-derived PC-based nanocomposites as MAMs such as $\mathrm{Co}, \mathrm{Ni}, \mathrm{Fe}, \mathrm{Zn}, \mathrm{Cu}, \mathrm{Ti}, \mathrm{Zr}$ and rare-earth (RE) MOF-derived PC-based nanocomposites. Besides the pure MOF, multi-metal MOF or tunable chemical composition incorporated with other loss material had also been fabricated as MAMs. Furthermore, MAMs with different morphology had been reviewed. Finally, we put forward some personal insights into the current status and perspectives in the future research direction.

\section{Theories of Microwave Absorption}

When the incident EMW contacts with the surface of the MAMs, as shown in Fig. 1, three situations may happen. Part of the incident EMW reflects on the surface of the MAMs (reflected EMW), part of it goes to the interior of the MAMs and absorbed by the MAMs (adsorbed EMW), and the rest of the EMW goes through the MAMs (transmitted EMW) [48]. When designing MAMs, researchers expect the incident EMW to be dissipated as much as possible inside the MAMs to reduce reflected EMW and transmitted EMW. Therefore, a good MAM usually needs to meet two conditions: good impedance matching and strong EMW attenuation ability $[49,50]$. The good impedance matching requires incident EMW goes into the MAMs as much as possible and reduces the reflection on the material surface [51]. The ideal impedance matching requires that the complex permittivity $\left(\varepsilon_{r}=\varepsilon^{\prime}-j \varepsilon^{\prime \prime}\right)$ is equal to the complex permeability $\left(\mu_{r}=\mu^{\prime}-j \mu^{\prime \prime}\right)$. In the formula, $\varepsilon^{\prime}$ and $\mu^{\prime}$ represent the ability to store electrical and magnetic energy, while $\varepsilon^{\prime \prime}$ and $\mu^{\prime \prime}$ refer to the loss of electrical and magnetic energy [52, 53]. 


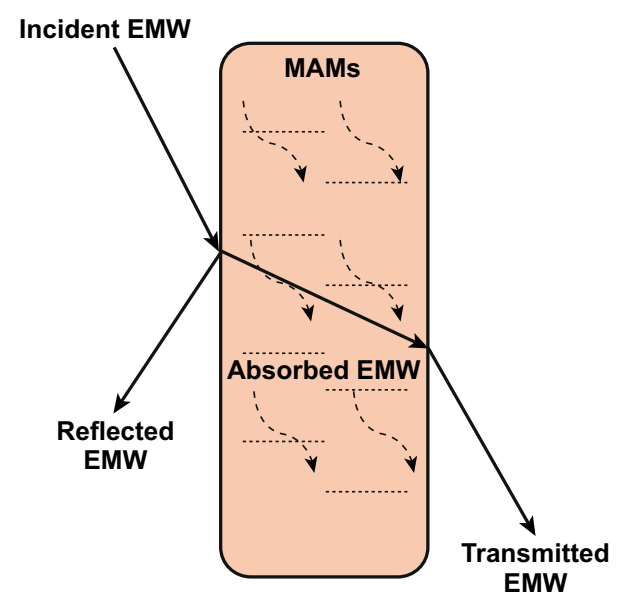

Fig. 1 Schematic diagram of interaction between MAMs and microwaves

It is not easy to meet this requirement. We can artificially adjust electromagnetic parameters ( $\varepsilon$ and $\mu$ ) to improve the impedance matching. The EMW attenuation ability means the loss capacity of the EMW which enters into the interior of MAMs [24, 54, 55].

Reflection loss $(R L)$ is often used to evaluate the EMW absorption ability. For example, the $R L$ value of $-10 \mathrm{~dB}$ is comparable to $90 \%$ of $\mathrm{MA}$, and the $R L$ value of $-20 \mathrm{~dB}$ is comparable to $99 \%$ of MA. The $R L$ is calculated by the transmission line theory, which is shown as follows [56-60]:

$Z=\left|Z_{\text {in }} / Z_{0}\right|=\left|\sqrt{u_{r} / \varepsilon_{r}} \tanh \left[j\left(2 \pi f d / c \sqrt{\varepsilon_{r} u_{r}}\right)\right]\right|$

$R_{L}=20 \log \left|\left(Z_{\text {in }}-Z_{0}\right) /\left(Z_{\text {in }}+Z_{0}\right)\right|$

$Z_{0}$ is the impedance of free space $(377 \Omega), Z_{\text {in }}$ is the input impedance of MAMs, $f$ is the frequency of EMW, $d$ is the thickness of the MAMs, and $c$ is velocity of light, respectively. When $Z=1$, the wave impedance of the MAMs is exactly the same as that of the free space. The incident EMW can enter the MAMs completely without reflected wave. Therefore, $Z=1$ is an ideal situation. When the value of $Z$ is equal or close to 1 , it is beneficial for improving MA ability $[61,62]$. The delta-function is another method to evaluate the EM impedance matching degree. The equation is shown as follows [63-65]:

$|\Delta|=\left|\sinh ^{2}(K f d)-M\right|$
$K=\frac{4 \pi \sqrt{\mu_{r}^{\prime} \varepsilon_{r}^{\prime}} \times \sin \left(\frac{\delta_{e}+\delta_{m}}{2}\right)}{c \times \cos \delta_{e} \times \cos \delta_{m}}$

$M=\frac{4 \mu_{r}^{\prime} \varepsilon_{r}^{\prime} \cos \delta_{e} \times \cos \delta_{m} \sqrt{\mu_{r}^{\prime} \varepsilon_{r}^{\prime}} \times \sin \left(\frac{\delta_{c}+\delta_{m}}{2}\right) 4 \mu_{r}^{\prime} \varepsilon_{r}^{\prime} \cos \delta_{e} \times \cos \delta_{m} \sqrt{\mu_{r}^{\prime} \varepsilon_{r}^{\prime}} \times \sin \left(\frac{\delta_{e}+\delta_{m}}{2}\right)}{\left(\mu_{r}^{\prime} \cos \delta_{e}-\varepsilon_{r}^{\prime} \cos \delta_{m}\right)^{2}+\left[\tan \left(\frac{\delta_{e}-\delta_{m}}{2}\right)\right]^{2}\left(\mu_{r}^{\prime} \cos \delta_{e}+\varepsilon_{r}^{\prime} \cos \delta_{m}\right)^{2}}$

The small delta value and close to zero indicate good impedance matching. If $|\Delta|$ tends to far away from zero, it gives poor microwave absorption.

The MAMs can be roughly divided into three types according to their loss mechanisms including dielectric loss materials, magnetic loss materials and multiple loss materials, as shown in Table 1. Dielectric loss materials are represented by carbon materials [66, 67], non-magnetic metal powder [68, 69], polymers [70, 71], non-magnetic metal oxides [72, 73], non-oxygen ceramics $[74,75]$ and so on. They possess features such as high strength, resistance to high temperature, excellent electrical conductivity and low density, but effective absorption bandwidth (EAB) and the MA performance may be not sufficient [76, 77]. Magnetic loss materials are represented by magnetic metal powder and compounds [78, 79], ferrite [80-87], carbonyl iron [88-90] and so on. However, their high density and poor stability limit their practical application [91]. The dielectric and magnetic loss factors, defined as $\tan \delta_{E}=\varepsilon^{\prime \prime} / \varepsilon^{\prime}$ and $\tan \delta_{M}=\mu^{\prime \prime} / \mu^{\prime}$, are suggested to evaluate on dielectric and magnetic losses [92-94].

The dielectric loss ability mainly stems from electrical conductivity loss and polarization relaxation loss [95, 96]. The electrical conductivity loss is that when the EMWs enters into the MAMs, the charge carriers would form a current under the action of the electric field, and then, the electric energy converts to the thermal energy or other form of energy and dissipated out [97, 98], thus increasing EMW attenuation. However, if the conductivity is too high, the incident EMW will be reflected by a large amount, resulting in impedance mismatch and poor EMW attenuation. The polarization relaxation loss is split into ionic polarization, electronic polarization, dipoles relaxation polarization and interfacial polarization (spatial polarization) [55, 99]. Ion polarization is caused by the relative displacement of cations and anions. Electron polarization is caused by position change of the constituent atoms relative to the nucleus, and thus, the dipole moment is generated. Ion polarization and electron polarization usually occur in the frequency range of 
Table 1 Classification table of common MAMs

\begin{tabular}{lll}
\hline Types of MAMs & Typical materials & Loss mechanisms \\
\hline $\begin{array}{ll}\text { Dielectric loss material } \\
\text { Carbon materials, non-magnetic metal powder, polymer, } \\
\text { non-magnetic metal oxides, non-oxygen ceramics, etc. }\end{array}$ & $\begin{array}{c}\text { Electrical conductivity loss, polarization relaxation loss } \\
\text { (dipoles relaxation polarization and interfacial polariza- } \\
\text { tion) }\end{array}$ \\
$\begin{array}{l}\text { Magnetic loss material } \\
\text { Multiple loss material }\end{array}$ & $\begin{array}{l}\text { Magnetic metals and compounds, ferrite, carbonyl iron, etc. } \\
\text { Combination of the above }\end{array}$ & $\begin{array}{l}\text { Hysteresis loss, eddy current loss and residual loss } \\
\text { Multiple loss }\end{array}$ \\
\hline
\end{tabular}

ultraviolet, visible and infrared light, which is much higher than the microwave frequency range $(2-18 \mathrm{GHz})$, so they are excluded $[100,101]$. Dipoles relaxation polarization refers to the polarization caused by the rotation of the dipole moment in the direction of the electric field, and it can greatly influence the dielectric loss $[41,102]$. The relaxation loss can be analyzed by Debye equation [103-105]:

$$
\begin{aligned}
& \varepsilon^{\prime}=\varepsilon_{\infty}+\left(\varepsilon_{S}-\varepsilon_{\infty}\right) \frac{1}{1+\omega^{2} \tau^{2}} \\
& \varepsilon^{\prime \prime}=\left(\varepsilon_{S}-\varepsilon_{\infty}\right) \frac{\omega \tau}{1+\omega^{2} \tau^{2}}
\end{aligned}
$$

We can deduce an equation from Eqs. (3) and (4) as follows:

$$
\left(\varepsilon^{\prime}-\frac{\varepsilon_{S}+\varepsilon_{\infty}}{2}\right)^{2}+\left(\varepsilon^{\prime \prime}\right)^{2}=\left(\frac{\varepsilon_{S}-\varepsilon_{\infty}}{2}\right)^{2}
$$

where $\varepsilon_{S}$ is the static dielectric constant, $\varepsilon_{\infty}$ is the dielectric constant of infinite frequency, and $\tau$ is the time of relaxation. The circle of this equation is called Cole-Cole semicircle $[106,107]$. Each Cole-Cole semicircle represents a polarization relaxation process $[108,109]$. The points on the semicircle correspond to the values of the real and imaginary parts of the dielectric constant at a certain frequency calculated by the Debye equation. Interfacial polarization usually appears at the interface of heterogeneous medium, which is caused by the accumulation of electrons or ions at the interface under the action of the external electric field [110]. Generally speaking, dielectric materials can be wideband absorption. However, the disadvantage is that the low-frequency absorption effect is poor and it is difficult to achieve the thin coating wideband absorption.

Magnetic loss refers to the phenomenon that the work is done by the outside world to a magnetic material and then the work is converted into heat during the process of magnetization or demagnetization [111]. It includes hysteresis loss, eddy current loss and residual loss $[112,113]$. The hysteresis loss is due to the hysteresis loop relationship between the magnetic perceptual strength and the magnetic field strength. Normally, the hysteresis loss often occurred in the weak field can be excluded [114]. When a conductor moves in an inhomogeneous magnetic field or is in a time-varying magnetic field, the energy loss caused by the induced current in the conductor is called eddy current loss. It can be defined as [115-117]:

$C_{0}=\frac{\mu^{\prime \prime}}{\left(\mu^{\prime}\right)^{2} f}=\frac{2}{3} \pi \mu^{0} \delta d^{2}$

where $\delta$ is the electrical conductivity of material, and $d$ is the thickness of the MAMs. From the equation, $C_{0}$ is a constant at a certain thickness of the MAMs with the change of frequency. This is one of the ways to determine whether EMW loss only results from the eddy current loss [118]. The residual loss refers to other losses except hysteresis loss and eddy current loss [77, 101].

The multiple loss material is not just a single loss mechanism, and it combined the advantages of various losses.

We all know that the synergistic effects between the dielectric loss and magnetic loss contribute to the excellent EMW absorption ability, which result in the good impedance matching and strong EM wave attenuation of the MAMs. However, the conflict between the two sides is still exist. In order to get the EMW into the material as much as possible, it will inevitably reduce the attenuation ability of the MAMs to the EMW. Therefore, it is necessary to coordinate impedance matching and EMW attenuation in practical application. The attenuation constant $\alpha$ can be defined as $[119,120]$ :

$\alpha=\frac{\sqrt{2} \pi f}{c} \sqrt{\left(\mu^{\prime \prime} \varepsilon^{\prime \prime}-\mu^{\prime} \varepsilon^{\prime}\right)+\sqrt{\left(\mu^{\prime \prime} \varepsilon^{\prime \prime}-\mu^{\prime} \varepsilon^{\prime}\right)^{2}+\left(\mu^{\prime \prime} \varepsilon^{\prime \prime}+\mu^{\prime} \varepsilon^{\prime}\right)^{2}}}$

Dissipation of reflected EMW through the interference of MAMs is another key factor to attenuate the EMW, which can be described by the quarter-wavelength matching mechanism $(\lambda / 4)$ as follows $[46,109]$ : 
$d_{m}=\frac{n \lambda}{4}=\frac{n c}{4 f_{m} \sqrt{\left|\mu_{r}\right|\left|\varepsilon_{r}\right|}}(n=1,3,5)$

In the formula, $\lambda$ is the wavelength of EMW, $d_{m}$ and $f_{m}$ are the thickness and corresponding frequency of maximum RL values, and $\left|\mu_{r}\right|$ and $\left|\varepsilon_{r}\right|$ are the modulus of complex permeability and permittivity at $f_{\mathrm{m}}$, respectively.

\section{MOF-Derived PC-Based Nanocomposites as MAMs}

As we know, MOFs are composed of inorganic metal center (metal ion or metal cluster) and organic ligand [121, 122]. Through direct pyrolysis of MOFs, they can be converted into metal-doped carbon, and the structure does not change significantly. We can simple and fast synthesis of MAMs by pyrolysis. However, the pure MOF-derived PC-based nanocomposites have not been functionalized, the absorption loss mechanism is simple and MA performance may be not exciting. By incorporated with materials with different absorbing loss mechanisms, impedance matching can be improved and the MA performance can be enhanced.

\subsection{Magnetic Single-Metal MOF-Derived PC-Based Nanocomposites as MAMs}

Common magnetic metals are $\mathrm{Fe}$, Co and Ni. They often act as inorganic metal centers to synthesize MOF. When they are directly pyrolyzed, the MA performance may not be very good because the simple loss mechanism may lead to impedance mismatch. They often coupled with dielectric loss material to improve impedance matching and rational design on the microstructure to introduce multiple loss mechanisms.

\subsubsection{Co-MOF-Derived PC-Based Nanocomposites as MAMs}

The most widely studied MOF-derived PC-based nanocomposites as MAMs are the Co-MOF. The typical Co-MOF is ZIF (zeolitic imidazolate framework)-67, which is prepared through the self-assembly of $\mathrm{Co}^{2+}$ and 2-methylimidazole. In Kuang's work, they pyrolyze Co-based MOFs (Co-MOF,
ZIF-67) to synthesize porous $\mathrm{Co} / \mathrm{C}$ composite under inert atmosphere with different pyrolysis temperature [123]. The morphology before and after sintering has not changed much, just the surface was wrinkled, as shown in Fig. 2. The sample pyrolysis at $500{ }^{\circ} \mathrm{C}$ shows better MA performance. The maximum $R L$ of $\mathrm{Co} / \mathrm{C}-500$ reached $-35.3 \mathrm{~dB}$ at $5.8 \mathrm{GHz}$ with a thickness of $4 \mathrm{~mm}$, and the $E A B$ was $5.80 \mathrm{GHz}(8.40-14.20 \mathrm{GHz})$ corresponding to a thickness of $2.5 \mathrm{~mm}$. The magnetic loss of Co, the large dielectric loss value of carbon and the porous structure result in the MA performance, but the $R L$ and $E A B$ are not very satisfactory.

Since the tunable of inorganic metal center and organic ligand, MOFs have various of compositions and structures. Co-MOF-derived PC-based nanocomposites as MAMs have been reported by many groups. Kong synthesized $\mathrm{Co} / \mathrm{C}$ pyrolysis from the cubic $\left[\mathrm{Co}(\mathrm{INA})_{2}\right] \mathrm{MOF}$ by isonicotinic acid as organic ligand [124]. Wang's group constructed $\mathrm{Co} / \mathrm{C}$ composites via pyrolysis a new Cobased MOF named $\left.\left[\mathrm{Co}_{2} \mathrm{O} \text { (cptpy) }\right)_{2}(\mathrm{DMF})\right]$ (CPT-1-Co, Hcptpy $=4^{\prime}$-(4-carboxy phenyl)-4,2':6',4'-terpyridine, $\mathrm{DMF}=\mathrm{N}, \mathrm{N}$-dimethylformamide), by reacting a multi-dentate ligand, 4'-(4-carboxyphenyl)-4,2':6',4"'-terpyridine (Hcptpy), with $\mathrm{Co}(\mathrm{OAc})_{2}$ salt [125]. More works of $\mathrm{Co} / \mathrm{C}$ synthesized from pure Co-MOF have also been reported [126, 127]. However, the MA performance of pure Co-MOF-derived PC-based nanocomposites is not quite satisfying. The reason may be the low relatively complex permittivity, and high relatively complex permeability leads to poor impedance matching performance, thus limiting their application in MAMs. So, Co-MOF coupled with other loss material, especially dielectric loss material, is a better solution to improve the MA performance.

When they coupled with MOF-derived PC, they would show unexpected performance. The MOF-derived PC/ dielectric loss material nanocomposites have many advantages, such as low cost, easy preparation and low density. Moreover, the additional loss mechanisms are created, and electrical loss, polarization loss, the interfacial and multiple scattering may lead to the good MA performance.

Carbon materials such as graphene, carbon nanotube (CNT) and carbon nanofiber (CNF) have aroused wide attention as MAMs due to their excellent physical and chemical properties, including their lightweight, high specific surface area, mechanical strength, thermal stability, corrosion resistance, electric conductivity and dielectric properties. Graphene, composed of $s p^{2}$-bonded carbon atoms, has a lot of advantages such as electrical, thermal 

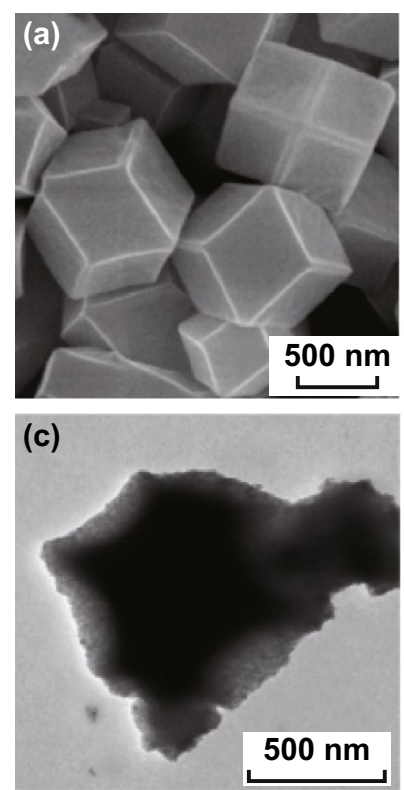

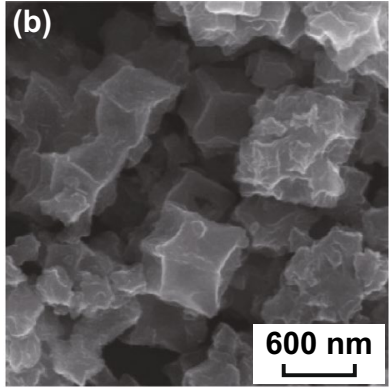

(d)

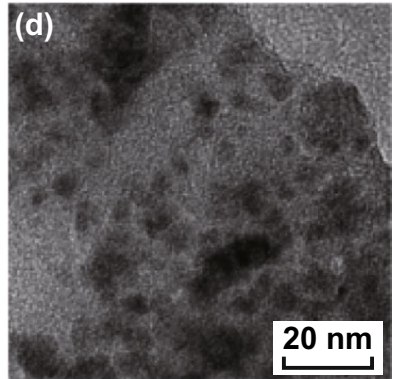

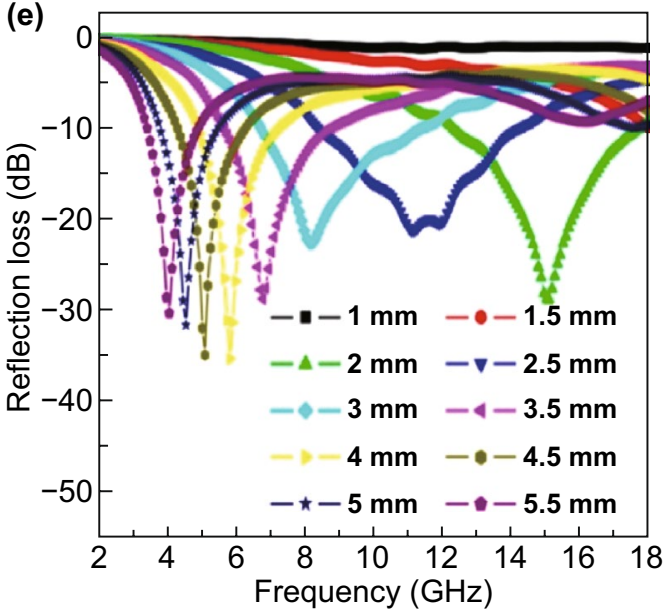

Fig. 2 a, b SEM images of $\mathrm{Co} / \mathrm{C}$ before and after calcination at $500{ }^{\circ} \mathrm{C}$ under Ar for $5 \mathrm{~h}$. c, d Low and high magnification TEM images of $\mathrm{Co} / \mathrm{C}-500$. e Calculated results of the reflection loss vs frequency for Co/C-500 with different thicknesses. Reprinted with permission from Ref. [123]

and mechanical properties. Graphene has functional groups and some defects on its surface. The impedance matching of graphene can be improved, and the dipole polarization relaxation can also be generated to improve the MA performance. Graphene can also form a multilayer structure, which can increase the number of reflections and propagation distance of EMW. Dong had synthesized MOF/RGO hybrids by two steps including in situ growth of Co-based MOF on GO nanosheets and a controlled calcination process [128], which is shown in Fig. 3. The maximum $R L$ of the sample reached $-52 \mathrm{~dB}$ at $9.6 \mathrm{GHz}$ with a thickness of $4.1 \mathrm{~mm}$. The $E A B$ of this MOF/RGO hybrid can reach $7.72 \mathrm{GHz}$ only under a thickness of $3.2 \mathrm{~mm}$, which surpasses most reported MOF and RGO-based MAMs. It is worthy to point out that the enhanced effect of MOF/ RGO interface, improved match between dielectric loss and magnetic loss should be considered as the factor of the high MA performance.

Chen's group synthesized $\mathrm{CoC}-\mathrm{rGO}$ obtained by calcination of ZIF-67-GO hybrids [129]. The introduction of high conductivity of rGO may lead to strong eddy current loss and reduce the permeability. The impedance matching is determined by the additive amount of rGO. The $R L_{\max }$ value reached up to $-44.77 \mathrm{~dB}$ at thickness of $2.1 \mathrm{~mm}$, and the $E A B$ reached $5.2 \mathrm{GHz}$ at thickness of $1.8 \mathrm{~mm}$, which showed evident advantages compared to $\mathrm{CoC}$ or rGO alone with single loss mechanism. Zhang's group synthesized MOF-derived carbonaceous $\mathrm{Co}_{3} \mathrm{O}_{4} / \mathrm{Co} / \mathrm{RGO}$ composite at $600{ }^{\circ} \mathrm{C}$ in $\mathrm{Ar}$ [130]. The sample displays $R L_{\max }-52.8 \mathrm{~dB}$ at $13.12 \mathrm{GHz}$ with thickness which is only $2.0 \mathrm{~mm}$. The $E A B$ is up to $10.72 \mathrm{GHz}$ in the thicknesses range of $2.0-4.0 \mathrm{~mm}$. Since the unique porous structure, the dielectric and magnetic tangent losses of the sample are in the middle levels, it is beneficial for the impedance match and thus results in the higher MA performances. CNTs can be divided into single-walled carbon nanotubes (SCNTs) and multi-walled carbon nanotubes (MCNTs). They have a very large aspect ratio, so a conductive network can be formed. The dielectric constant is large, and its permeability is small, so its impedance matching is poor. Therefore, it is often combined with other magnetic loss materials to improve the MA performance. Dong et al. had prepared a 3D Co/C-MCNTs hybrid network using MCNTs as wires and Co-based MOFs as junctions [131]. The multiple components synergistic effect leads to the good MA performance. The purpose of introducing MCNTs may promote the formation of a conductive network, increasing interfacial polarization. The $R L_{\max }$ of the sample $\mathrm{Co} / \mathrm{C}$-MCNTs is $-33.4 \mathrm{~dB}$ at the frequency 
(a)

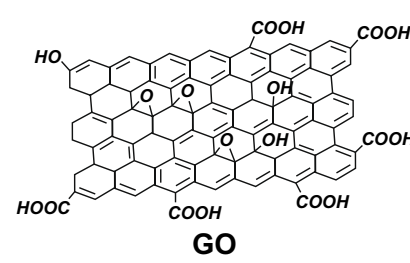

GO
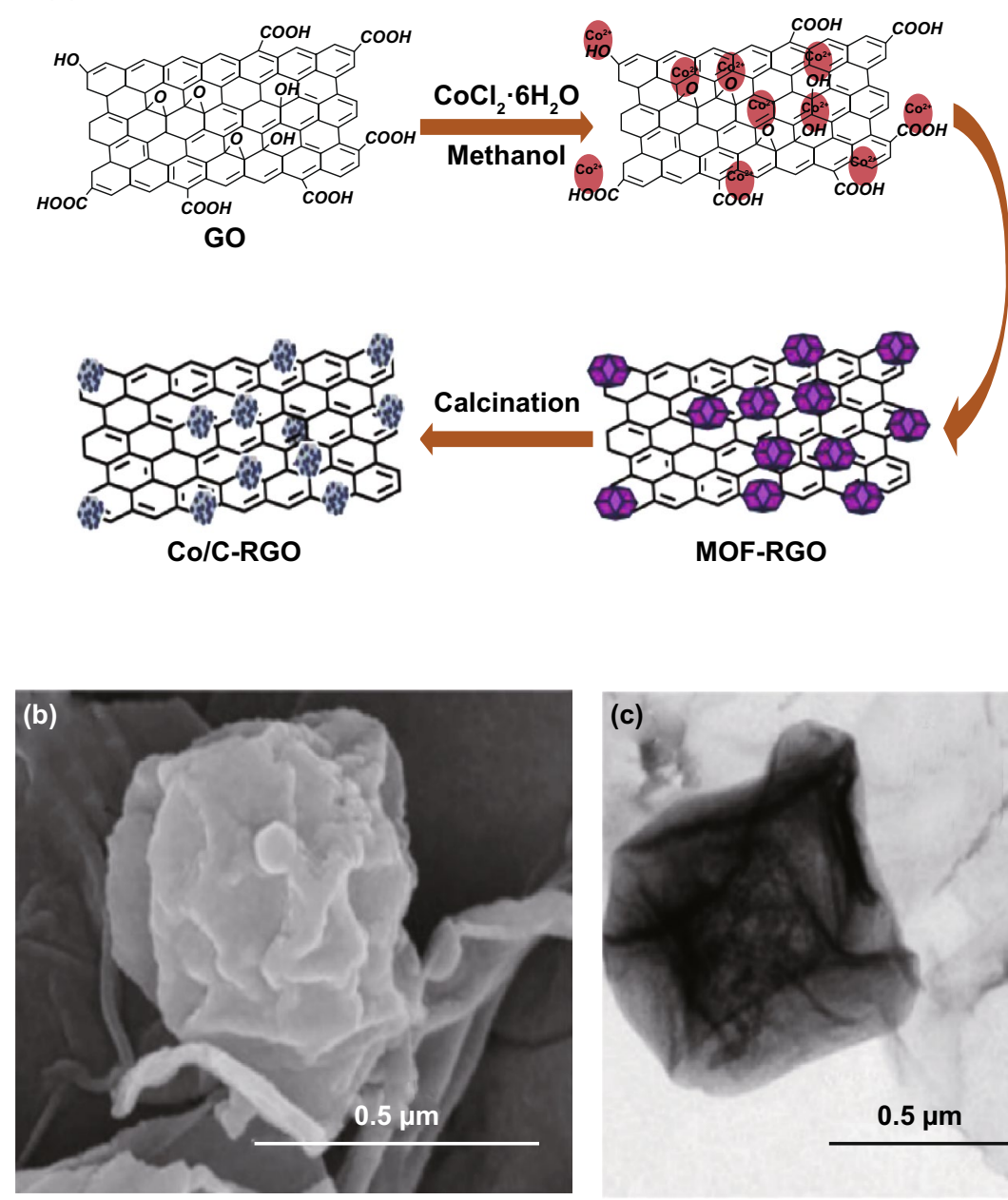
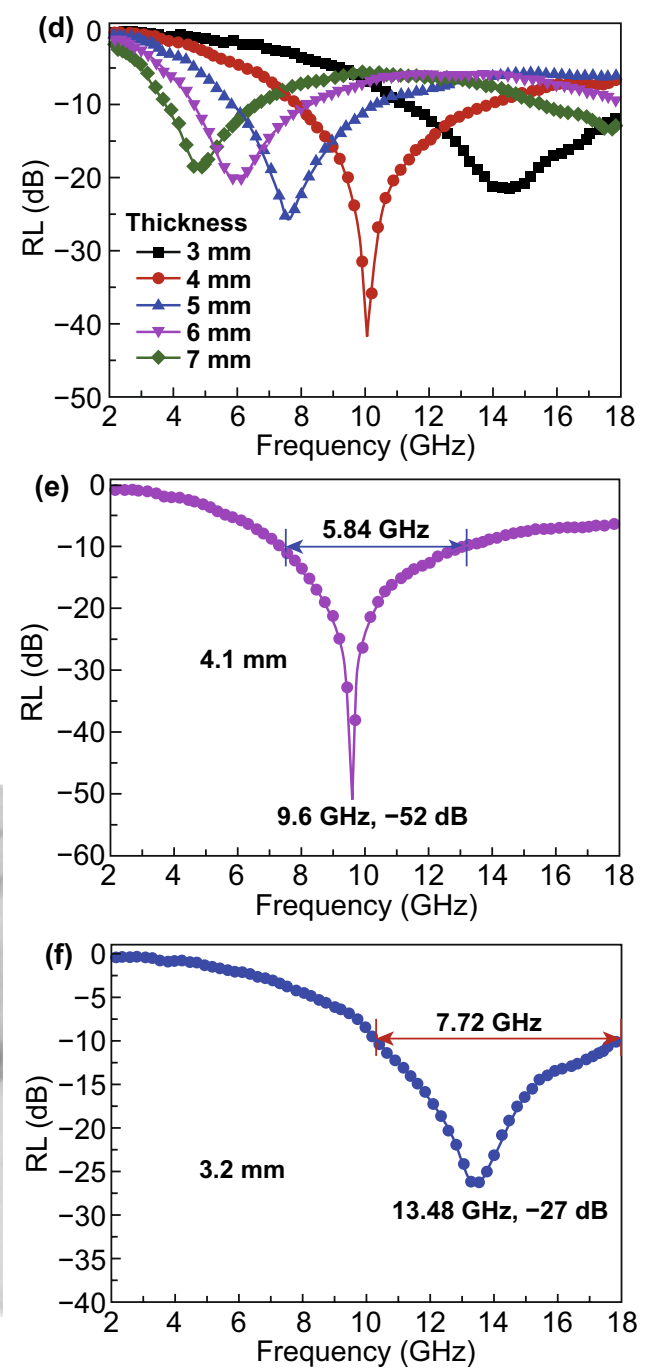

Fig. 3 a Process for the preparation of MOF/RGO. b, c SEM and TEM images of heat-treated MOF/GO hybrid at $500^{\circ} \mathrm{C}$ for $6 \mathrm{~h}$. d-f RL curves of MOF/GO-500 and under 3.2 and $4.1 \mathrm{~mm}$ with a filler loading ratio of $6 \mathrm{wt} \%$ in wax. Reproduced with permission from Ref. [128]

of $3.6 \mathrm{GHz}$ with the thickness of $6 \mathrm{~mm}$. And the EAB is $4.08 \mathrm{GHz}$ at $1.8 \mathrm{~mm}$. Yu had also fabricated Co-C/MWCNTs composites, and the $R L_{\max }$ is $-48.9 \mathrm{~dB}$ at $2.99 \mathrm{~mm}$ [132]. Tan synthesized ultra-small Co/CNTs nanohybrid via the pyrolysis of ZIF-67 and (catalytic chemical vapor deposition) CCVD method. It achieves the $R L_{\max }$ of $-49.16 \mathrm{~dB}$ and the in $\mathrm{EAB}$ of $4.2 \mathrm{GHz}(12.4-16.6 \mathrm{GHz})$ [133]. Chen synthesized MWCNTs@ carbonaceous CoO composites with good MA properties [134]. When the annealing temperature is 500 and $600{ }^{\circ} \mathrm{C}$, the carbonaceous $\mathrm{Co}_{3} \mathrm{O}_{4}$ can be obtained. When the annealing temperature is $700{ }^{\circ} \mathrm{C}, \mathrm{Co}_{3} \mathrm{O}_{4}$ was all reduced to $\mathrm{CoO}$. The value of $R L_{\max }$ is up to $-50.2 \mathrm{~dB}$ with $1.84 \mathrm{~mm}$ thickness. CNF has high dielectric constant, so the impedance match may be not very good, and we usually improve the MA performance by combining with magnetic loss materials. Zhang et al. reported necklace-like CNFs@ MOF-based carbonaceous $\mathrm{Co} / \mathrm{CoO}$ composite, which was synthesized by wet and pyrolysis method [135]. The optimum $R L$ value is $-53.1 \mathrm{~dB}$ at $6.56 \mathrm{GHz}$ with the thickness $3.54 \mathrm{~mm}$, and $E A B$ is up to $13.52 \mathrm{GHz}$ with the thickness range of $2.0-5.0 \mathrm{~mm}$. The unique structure will form many defects, which can generate much interfacial polarization, which lead to more dielectric loss. The small-sized nanoparticle can improve dipole polarization. And impedance matching is also optimized to improve the MA performance. 
Polymer has the advantages of low density, anti-corrosion and adjustable conductivity, and the electric conductivity and dielectric constant are high. So, it has shown promising prospect in the field of MAMs. In Wang's report, a chainlike PPy (Polypyrrole) aerogel decorated with MOF-based nanoporous Co/C (Co/C@PPy) has been successfully prepared by a self-assembled polymerization method [136]. The composite Co/C@PPy can reach the optimal $R L$ value of $-44.76 \mathrm{~dB}$ at $17.32 \mathrm{GHz}$ with the thickness of $2.0 \mathrm{~mm}$. And the $E A B$ of $6.56 \mathrm{GHz}(11.04-17.60 \mathrm{GHz})$ is achieved with the thickness of $2.5 \mathrm{~mm}$. The performance is attributed to a proper impedance matching and a high dielectric loss highly enhanced by the PPy aerogel. Besides, the unique chain-like PPy aerogel and the porous feature of $\mathrm{Co} / \mathrm{C}$ itself can induce more multiple reflection and scattering of EMW.

Non-magnetic metal oxide is a common dielectric loss material and coupled with magnetic loss material to regulate impedance matching which is an effective strategy to solve the absorption problems. Zinc oxide ( $\mathrm{ZnO})$, as an important semiconductor with a wide band gap, has been extensively investigated as MAMs, due to its excellent dielectric properties and lightweight [137]. Hu's group constructed a novel 3D hetero-structured Co/NPC@ZnO/rGO by the direct pyrolysis of ZIF-67@ZnO NPs wrapped on rGO nanosheets [138]. ZnO can be utilized to regulate the complex permittivity over the measured frequency range and upgrade the impedance matching property of the sample. The $R L_{\max }$ can reach up to $-45.4 \mathrm{~dB}$ at only $2 \mathrm{~mm}$, and the $E A B$ achieved $5.4 \mathrm{GHz}$ (from 11.9 to $17.3 \mathrm{GHz}$ ). Vanadium sesquioxide $\left(\mathrm{V}_{2} \mathrm{O}_{3}\right)$, with relatively high electrical conductivity at room temperature and superior dielectric loss, is usually used in the field of MAMs. Yan's group designed and synthesized $\mathrm{Co} / \mathrm{C} @ \mathrm{~V}_{2} \mathrm{O}_{3}$ hollow spheres with an $R L$ of $-40.1 \mathrm{~dB}$ and the $E A B$ of $4.64 \mathrm{GHz}$ at a small thickness of only $1.5 \mathrm{~mm}$ [139]. The sample exhibits both excellent impedance matching and light weight due to the rational combination of hollow $\mathrm{V}_{2} \mathrm{O}_{3}$ spheres and porous $\mathrm{Co} / \mathrm{C}$. One-dimensional chainlike MnO@Co/C composite derived from $\mathrm{MnO}_{\mathrm{x}} @ \mathrm{ZIF}-67$ has also been reported [140]. Similar work was also reported by $\mathrm{Co} / \mathrm{N} / \mathrm{C} @ \mathrm{MnO}_{2}$ sample [141]. Hierarchical $\mathrm{MnO}_{2}$ sheets are used to decrease the excessive complex permittivity of $\mathrm{Co} / \mathrm{N} / \mathrm{C}$ and improving impedance match, and polydopamine (PDA) is carbon source. The sample with a filler loading of $15 \mathrm{wt} \%$ shows the $R L_{\max }$ of $-58.9 \mathrm{~dB}$ and $E A B$ of $5.5 \mathrm{GHz}$. The excellent MA performance of $\mathrm{Co} / \mathrm{N} / \mathrm{C} @ \mathrm{MnO}_{2}$ composites is attributed to synergetic effects of excellent impedance match, and dramatical EM attenuation ability arises from multiple helpful constituents, abundant interfaces and extraordinary hollow structure.

Non-oxygen ceramics presents high strength, good thermal stability and chemical resistivity. But the MA performance is not very good. In order to improve the MA performance, we usually combine non-oxygen ceramics with magnetic loss materials. Dong constructed kebab-like nanocomposites composed of $\mathrm{SiC}$ stringing polyhedral Co-MOF [142]. The excellent MA performance attributed to the reduced dielectric constant, enlarged aspect ratio and enhanced interface polarization. Under the thickness of $3 \mathrm{~mm}$, the $R L_{\max }$ attained $-47 \mathrm{~dB}$ at the frequency of $9.32 \mathrm{GHz}$, and the $E A B$ achieved $5.92 \mathrm{GHz}$ in a frequency range $12.08-18 \mathrm{GHz}$ with the sample thickness of $2.0 \mathrm{~mm}$.

Rational design on the microstructure of MOFs-derived PC-based nanocomposites is an effective strategy to prepare high-performance MAMs, through designing some special structures such as foam structure, core-shell structure and hollow structure, which improve the multiple reflections and interfacial polarization so as to enhance MA performance. Zheng's group successfully synthetized NRGO (nitrogen-doped)/MWCNT composite foams by hydrothermal and high-temperature calcination strategy [143]. The 3D networks were well constructed by overlapped flaky RGO in the composite foams, and the calcination temperature showed notable effects on the micromorphology. The $R L_{\max }$ is $-69.6 \mathrm{~dB}$ at $12.5 \mathrm{GHz}$, and EAB achieved $4.3 \mathrm{GHz}(13.2-17.5 \mathrm{GHz})$ at a low thickness of $1.5 \mathrm{~mm}$, as shown in Fig. 4. The excellent MA performance of the foams was derived from a well-constructed 3D network structure, nitrogen doping, polarization relaxation and conduction loss. Wu and his workmates designed a $3 \mathrm{D}$ hybrid carbon sponge composite with a hierarchical micro/nanostructure and hollow skeleton [144]. The conductive network, diverse interface, porous and tubular structures, as well as the synergistic effect between metallic Co nanocrystals and carbon species, resulting in the $R L_{\max }$ is $-51.2 \mathrm{~dB}$ with a ultrathin thickness of $1.6 \mathrm{~mm}$ and $E A B$ is $5.4 \mathrm{GHz}$. MOFs-derived hollow $\mathrm{Co} / \mathrm{C}$ microspheres were produced by Li's group [145]. They use cetyltrimethylammonium bromide (CTAB) as self-sacrificing template to make hollow microstructures well preserved in the resultant carbon matrix. The hollow microstructures improve the dielectric loss, magnetic loss and enhancing attenuation ability. So rational design on the microstructure of 

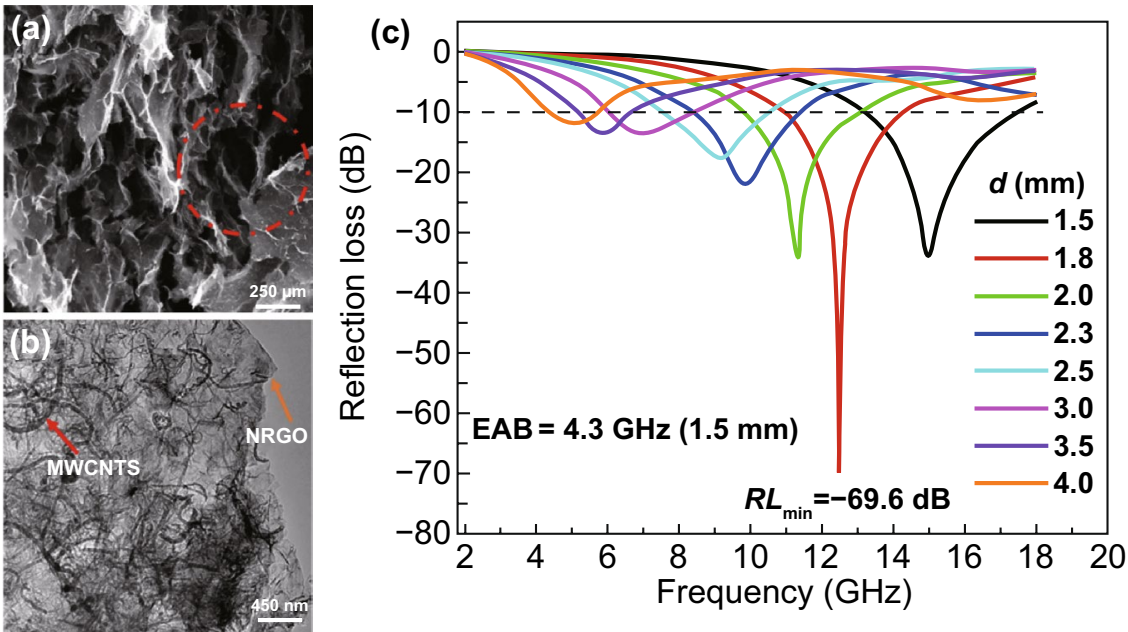

(d)

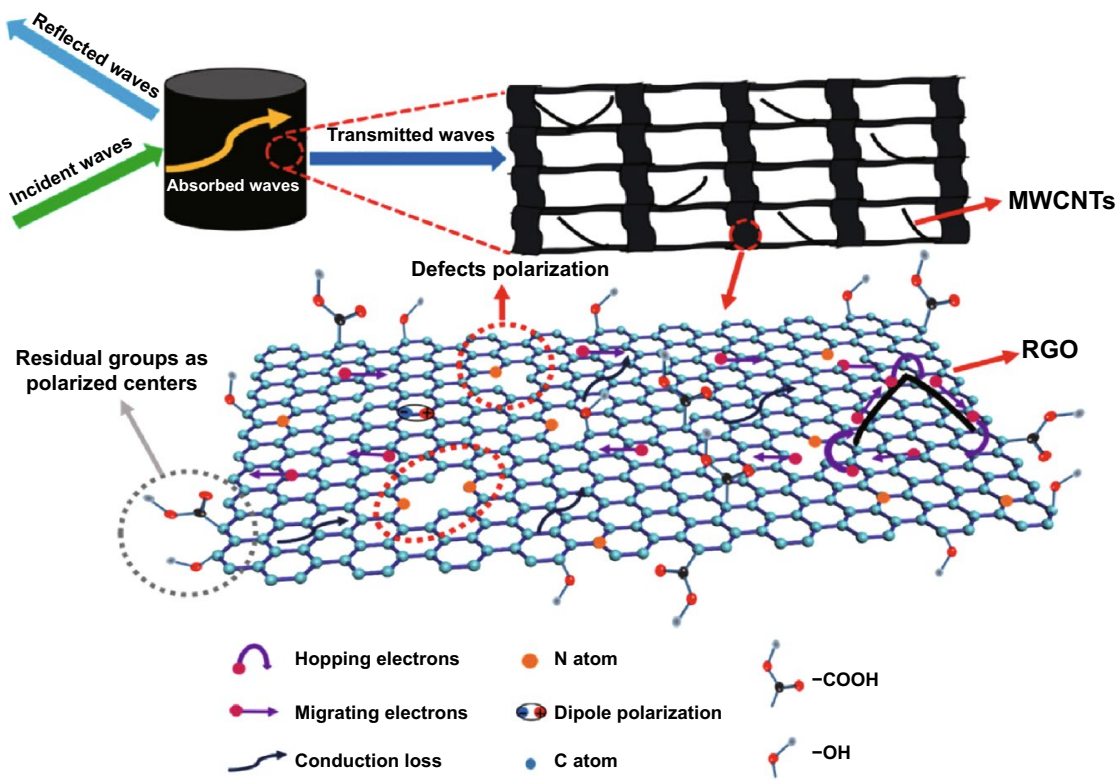

Fig. 4 a, b SEM and TEM images of the samples. c RL-f curves of the sample. d Schematic diagram of the EM absorbing mechanisms of NRGO/MWCNT composite foams. Reprinted with permission from Ref. [143]

MOFs-derived PC nanocomposites is an effective strategy to develop high-performance MAMs.

\subsubsection{Ni-MOF-Derived PC-Based Nanocomposites as MAMs}

Magnetic metal Ni-based MOF is also often used in MAMs. Zou and his workmates synthesized Ni@C composites by thermal decomposition of pure Ni-MOF [146]. The sample which calcinated at temperature $800{ }^{\circ} \mathrm{C}$ showed a $R L_{\text {max }}$ of $-55.7 \mathrm{~dB}$, and the $E A B$ is $6.0 \mathrm{GHz}$ at a thickness of $1.85 \mathrm{~mm}$. The excellent MA performance is related to the hollow structure and the synergistic effect between carbon and nickel nanoparticles. Ji had fabricated Ni nanoparticlesembedded nanoporous carbon (NPC/Ni), and the sample prepared at $700{ }^{\circ} \mathrm{C}$ exhibits nice MA performance with the $R L_{\max }$ value of $-39.4 \mathrm{~dB}$ and $E A B$ of $4.2 \mathrm{GHz}$ [147]. In Yang's report, they synthesized Ni-based MOF hollow spheres with various surface morphologies via a simple hydrothermal method [148]. The surface morphologies are controlled by the hydrothermal reaction time. The surface morphologies are smooth, hair-like and rod-like corresponding to the reaction time which is 6,8 , and $10 \mathrm{~h}$, respectively. 
The $R L_{\max }$ of the $10 \mathrm{~h}$ sample reached $-58 \mathrm{~dB}$ at $6 \mathrm{GHz}$ with a thickness of $1.5 \mathrm{~mm}$, and the $E A B$ was $6.2 \mathrm{GHz}$ $(5-11.2 \mathrm{GHz})$ with a thickness of $4.6 \mathrm{~mm}$, as shown in Fig. 5. The difference in the surface morphologies results in variation of the magnetic anisotropy, which leads to multiresonance behavior of the permeability. Liu's group synthesized two kinds of Ni@C derived from the Ni-based MOFs with two kinds of organic ligands (dimethylimidazole as a ligand named as Ni-ZIF and trimesic acid as a ligand named as Ni-BTC) [149]. The $R L_{\max }$ of the Ni@C-ZIF microspheres is $-86.8 \mathrm{~dB}$ with the thickness of $2.7 \mathrm{~mm}$, and the $E A B$ was $7.4 \mathrm{GHz}(4-11.4 \mathrm{GHz})$ with the thickness ranging from 1.5 to $4.0 \mathrm{~mm}$. The impedance matching, multiple reflection, interfacial polarization among $\mathrm{Ni}$ and $\mathrm{C}$ and the $\mathrm{N}$-doping were beneficial to the excellent MA performance.

The dielectric loss material is also usually introduced to $\mathrm{Ni}-\mathrm{MOF}$ to improve impedance matching. Chen's group fabricated multi-component composite $\mathrm{SiC} / \mathrm{Ni} / \mathrm{NiO} / \mathrm{C}$ by annealing SiC NPs and the Ni-MOF in argon [150]. The maximum $R L$ is $-50.52 \mathrm{~dB}$ at $13 \mathrm{GHz}$ for a film thickness of $4.0 \mathrm{~mm}$, and the $E A B$ is $2.96 \mathrm{GHz}(14.76-17.72 \mathrm{GHz})$ with thickness of $2.5 \mathrm{~mm}$. The high permittivity of the $\mathrm{SiC} /$ $\mathrm{Ni} / \mathrm{NiO} / \mathrm{C}$ nanocomposites is expected to enhance absorption of EMW, as shown in Fig. 6. The excellent MA performance also stems from the multi-interface structure which provides interfacial polarization and plasmon resonance.

Structure design is also very important to improve the MA performance of Ni-MOF-derived PC. Du synthesized hierarchical yolk-shell nanostructure (NiO/Ni/GN@Air@ $\mathrm{NiO} / \mathrm{Ni} / \mathrm{GN}$ ) derived from Ni-MOF by solvothermal reactions [151]. This special structure can effectively enhance the MA performance. And it can also tune the dielectric properties of the NiO/Ni/GN@Air@NiO/Ni/GN composites to achieve good impedance matching. The $R L_{\max }$ of $-34.5 \mathrm{~dB}$ is obtained at $17.2 \mathrm{GHz}$ with the thin thickness of $1.7 \mathrm{~mm}$. And the $E A B$ can be obtained in the frequency
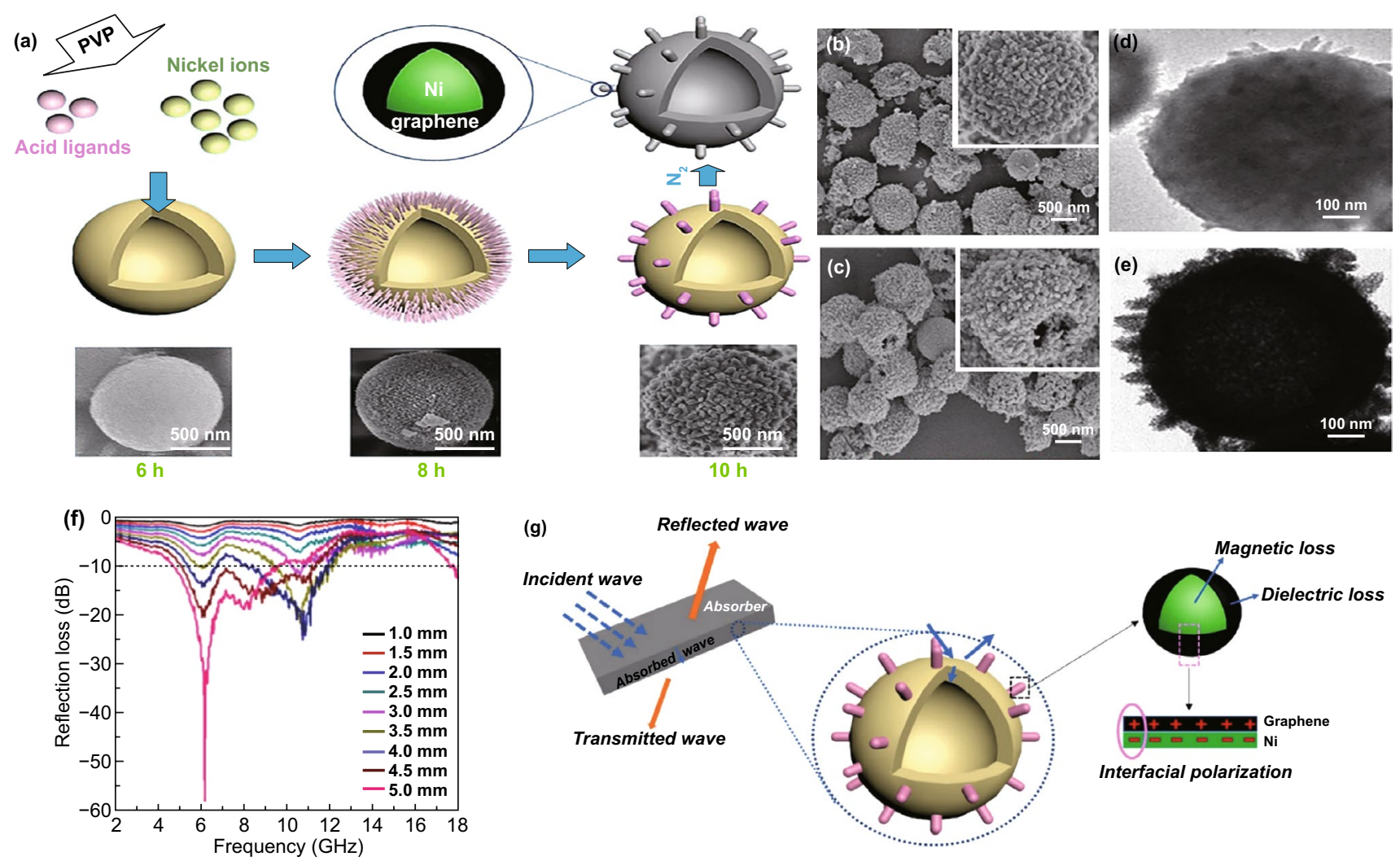

Fig. 5 a Illustration for the formation of Ni-MOF hollow spheres with controllable surface architecture. b, c SEM images and d, e TEM images of Ni-MOFs samples with $10 \mathrm{~h}$ before and after annealing at $600{ }^{\circ} \mathrm{C}$. f Electromagnetic wave reflection losses of the Ni-MOF sample with different reaction times. $g$ Absorbing mechanism of as-prepared samples. Reprinted with permission from Ref. [148] 

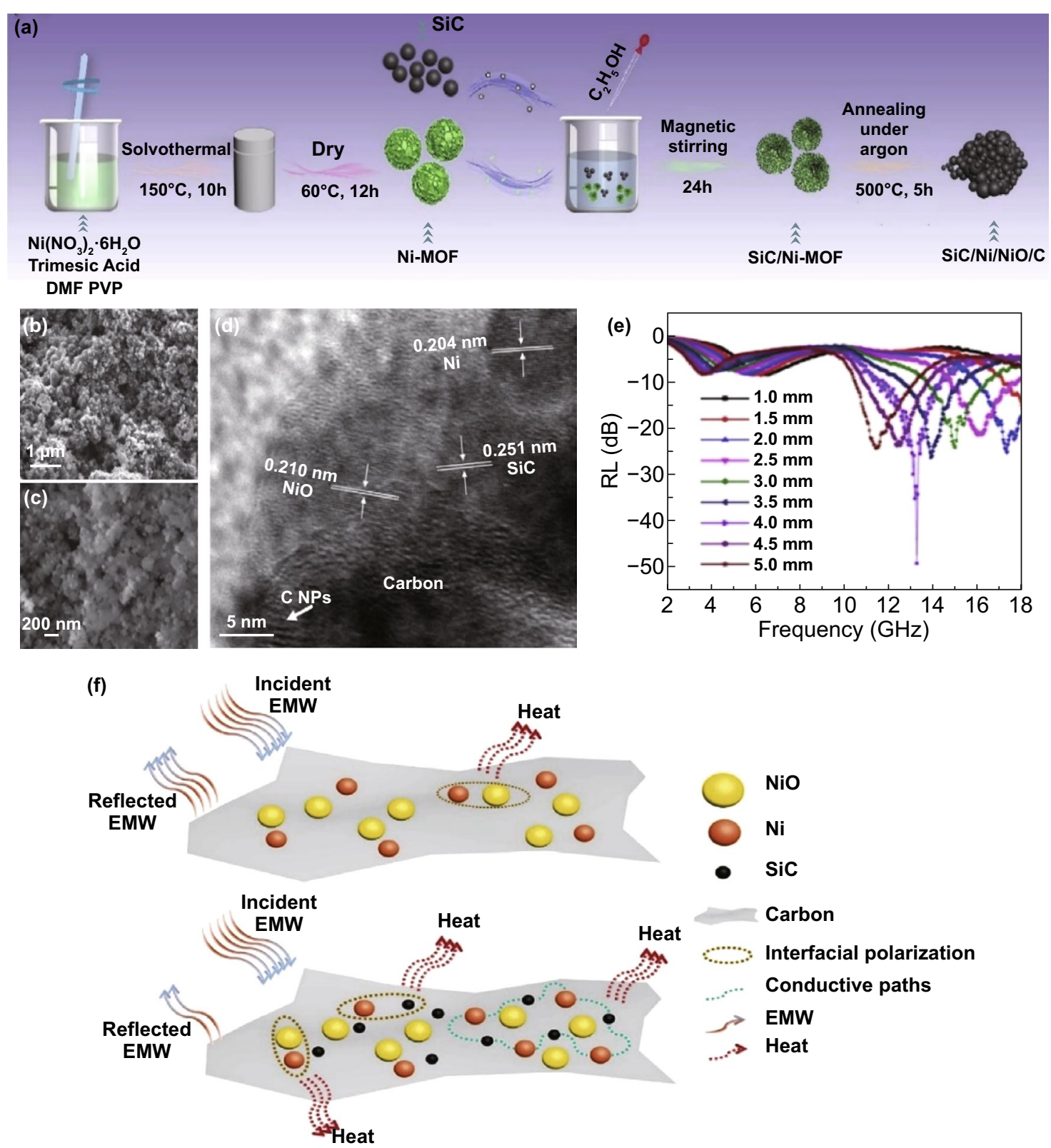

Fig. 6 a Preparation of the $\mathrm{SiC} / \mathrm{Ni} / \mathrm{NiO} / \mathrm{C}$ nanocomposites. b, c SEM images and d HRTEM image of the $\mathrm{SiC} / \mathrm{Ni} / \mathrm{NiO} / \mathrm{C}$ nanocomposites. e RL curves of $\mathrm{SiC} / \mathrm{Ni} / \mathrm{NiO} / \mathrm{C}$ with a filler loading of $20 \mathrm{wt} \%$ in paraffin. $\mathbf{f}$ Schematic of the electromagnetic wave (EMW) attenuation mechanisms of $\mathrm{Ni} / \mathrm{NiO} / \mathrm{C}$ and $\mathrm{SiC} / \mathrm{Ni} / \mathrm{NiO} / \mathrm{C}$ nanocomposites. Reprinted with permission from Ref. [150]

range $7.8-18 \mathrm{GHz}$ with absorber thicknesses of $1.7-5.0 \mathrm{~mm}$. The 3D porous flower-like Ni/C composites were prepared by Zou's group through the pyrolysis of Zn-doped Ni-MOF under $\mathrm{N}_{2}$ atmosphere [152]. These 3D flower-like structures have massive porous and large spacing flakes, which increases the EMW scatter. The $R L_{\max }$ is $-52.4 \mathrm{~dB}$ with a thickness of $1.6 \mathrm{~mm}$, and $E A B$ is $5 \mathrm{GHz}$.

\subsubsection{Fe-MOF-Derived PC-Based Nanocomposites as MAMs}

Because of the good chemical stability, high saturation magnetization and simple preparation, metal iron and ferrite are often used to enhance magnetic loss in MA. So dielectric loss material is also introduced to improve impedance 
matching. $\mathrm{Xu}$ et al. reported $\mathrm{Fe} / \mathrm{C}$ nanocubes, which are prepared through an in situ derivation from Prussian blue MOF by controlled high-temperature pyrolysis [153]. The maximum $R L$ of the sample obtained at $650{ }^{\circ} \mathrm{C}$ reached $-22.6 \mathrm{~dB}$ at $4 \mathrm{GHz}$ with a thickness of $5 \mathrm{~mm}$, and the EAB was $7.2 \mathrm{GHz}(10.8-18.0 \mathrm{GHz})$ corresponding to a thickness of $2 \mathrm{~mm}$, as shown in Fig. 7. The good MA performance of the $\mathrm{Fe} / \mathrm{C}$ nanocubes results in the synergetic effect of dielectric loss and magnetic loss.

Hu's group successfully fabricated magnetic $\mathrm{Fe}_{3} \mathrm{C} / \mathrm{C}$ (denoted as FC-650) and $\mathrm{Fe}_{3} \mathrm{C} / \mathrm{Fe} / \mathrm{C}$ (denoted as FC-700) carbon-matrix composites via carbonization of Material Institute Lavoisier (MIL)-101(Fe) [154]. Both $\mathrm{Fe}_{3} \mathrm{C} / \mathrm{C}$ and $\mathrm{Fe}_{3} \mathrm{C} / \mathrm{Fe} / \mathrm{C}$ owned flower-like structures formed by $2 \mathrm{D}$ flakes. $\mathrm{Fe}_{3} \mathrm{C} / \mathrm{C}$ possessed $R L_{\max }$ of $-39.43 \mathrm{~dB}$ at $14.00 \mathrm{GHz}$, at the thickness of $2.00 \mathrm{~mm}$. And the $E A B$ is $14.32 \mathrm{GHz}$ (from 3.68 to $18.00 \mathrm{GHz}$ ). The impedance matching and the welldesigned structures lead to the excellent MA performance.

The morphology usually had significant effect on the MA performance. Kong pyrolyzed two MOFs with different topologies (MOFs: MIL-101-Fe and MIL-88B-Fe) under same pyrolysis condition, identical chemical composition and microstructure [155]. The $R L_{\max }$ is $-59.2 \mathrm{~dB}$ with a thickness of $4.32 \mathrm{~mm}$, and the $E A B$ is $6.5 \mathrm{GHz}$ with a thickness of $2 \mathrm{~mm}$ which are achieved by Fe/C-700@101 (700: pyrolysis temperature; 101: MIL-101 precursor) and $\mathrm{Fe} /$ $\mathrm{Fe}_{3} \mathrm{C} / \mathrm{C}-800 @ 101$, respectively. This article reveals the significant impact of morphology on MA performance.

In order to improve the impedance matching, dielectric loss material is usually introduced to the Fe-MOF. Hu's group reported the synthesis of novel MOF (Fe)/PANI (polyaniline) core-shell composite via hydrothermal and in situ chemical polymerization methods [156]. The $R L_{\max }$ of the composite can reach $-41.4 \mathrm{~dB}$ at $11.6 \mathrm{GHz}$, and the $E A B$ is up to $5.5 \mathrm{GHz}$ with only $2 \mathrm{~mm}$. The loss mechanism is due to the enhanced interfacial polarization, dipole polarization and charge transfer and attenuation constant. The introduction of PANI enlarges the dielectric constant. Meanwhile, the higher dielectric constant of MOF $(\mathrm{Fe}) /$ PANI may be attributed to the improved interfacial polarization and appearance of localized defects as bipolaron/ polaron, and the multiple reflection and scattering in the

(a)
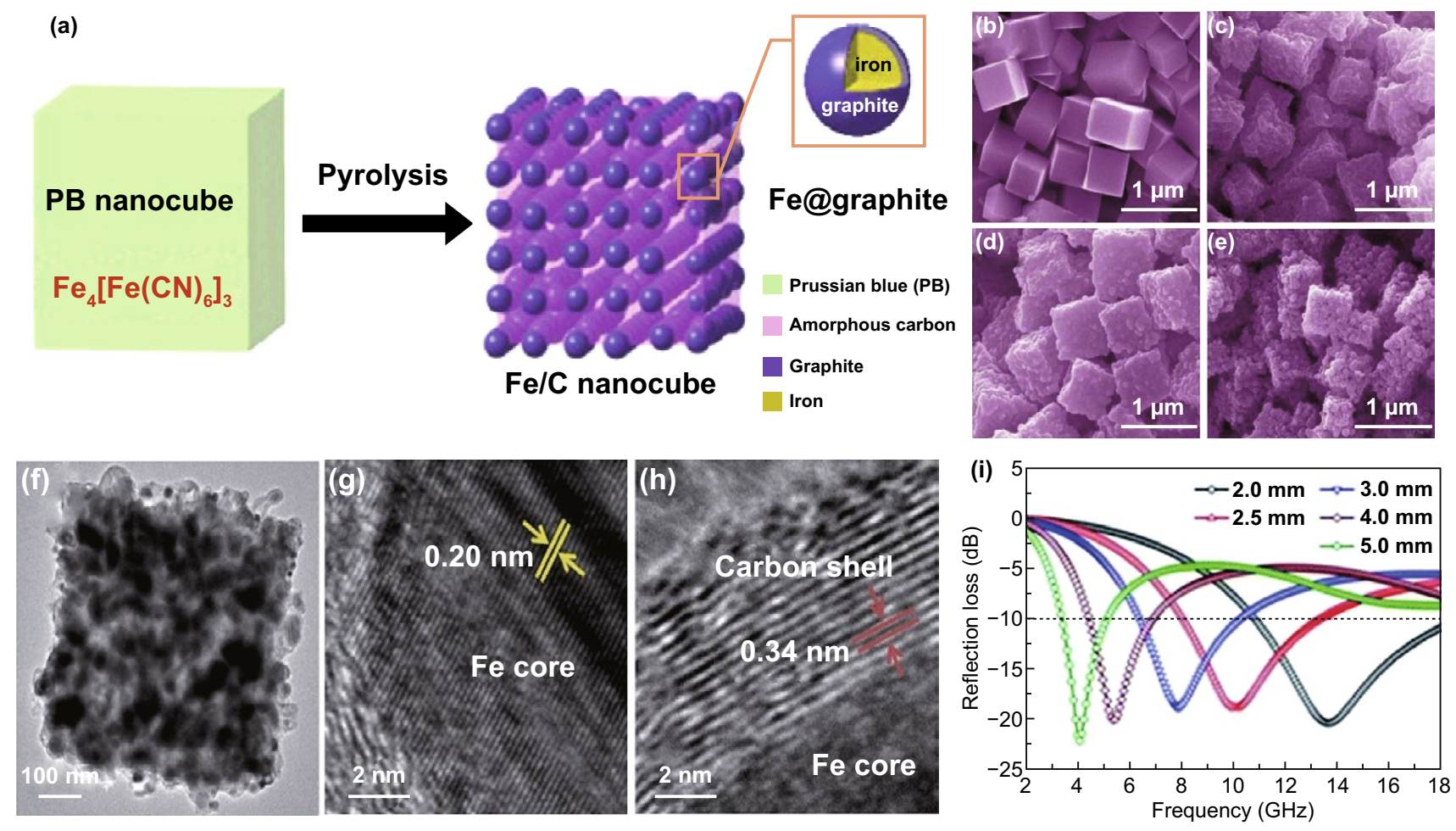

Fig. 7 a Schematic illustration of converting PB nanocubes into Fe/C nanocubes by a pyrolysis technique. b-e SEM images of the as-prepared $\mathrm{PB}$ nanocubes and $\mathrm{Fe} / \mathrm{C}$ nanocubes obtained at different pyrolysis temperatures: 600,650 and $700{ }^{\circ} \mathrm{C}$. $\mathbf{f}$ TEM image of the $650{ }^{\circ} \mathrm{C}$ sample. $\mathrm{g}$ HRTEM images of the Fe core and $\mathbf{h}$ the graphitic carbon shell. $\mathbf{i}$ Reflection losses of the $650{ }^{\circ} \mathrm{C}$ sample with variable absorber thicknesses. Reprinted with permission from Ref. [153] 
pores of the samples, dielectric loss, magnetic loss, good impedance matching also beneficial for EMW absorption. Lu's group reported $\mathrm{Fe}_{3} \mathrm{O}_{4} @$ carbon $\left(\mathrm{Fe}_{3} \mathrm{O}_{4} @ \mathrm{NPC}\right)$ composites by a simple one-pot synthesis method and subsequent in situ formation under thermal decomposition conditions [157]. The $\mathrm{Fe}_{3} \mathrm{O}_{4} @ \mathrm{NPC}$ composites exhibited MA performance with a maximum $R L$ of $-65.5 \mathrm{~dB}$ at $9.8 \mathrm{GHz}$ with a thickness of $3 \mathrm{~mm}$ and the $E A B$ of $4.5 \mathrm{GHz}$, as shown in Fig. 8. The tan $\delta_{\mathrm{m}}$ value was higher than $\tan \delta_{\varepsilon}$ value, which indicated that magnetic loss contributed more than dielectric loss to the EMW attenuation. Thus, the improvement of the absorption performance was mainly originated from the magnetic loss. The synergistic effects of the dielectric loss and the magnetic loss are effective in enhancing the MA performance.

(a)
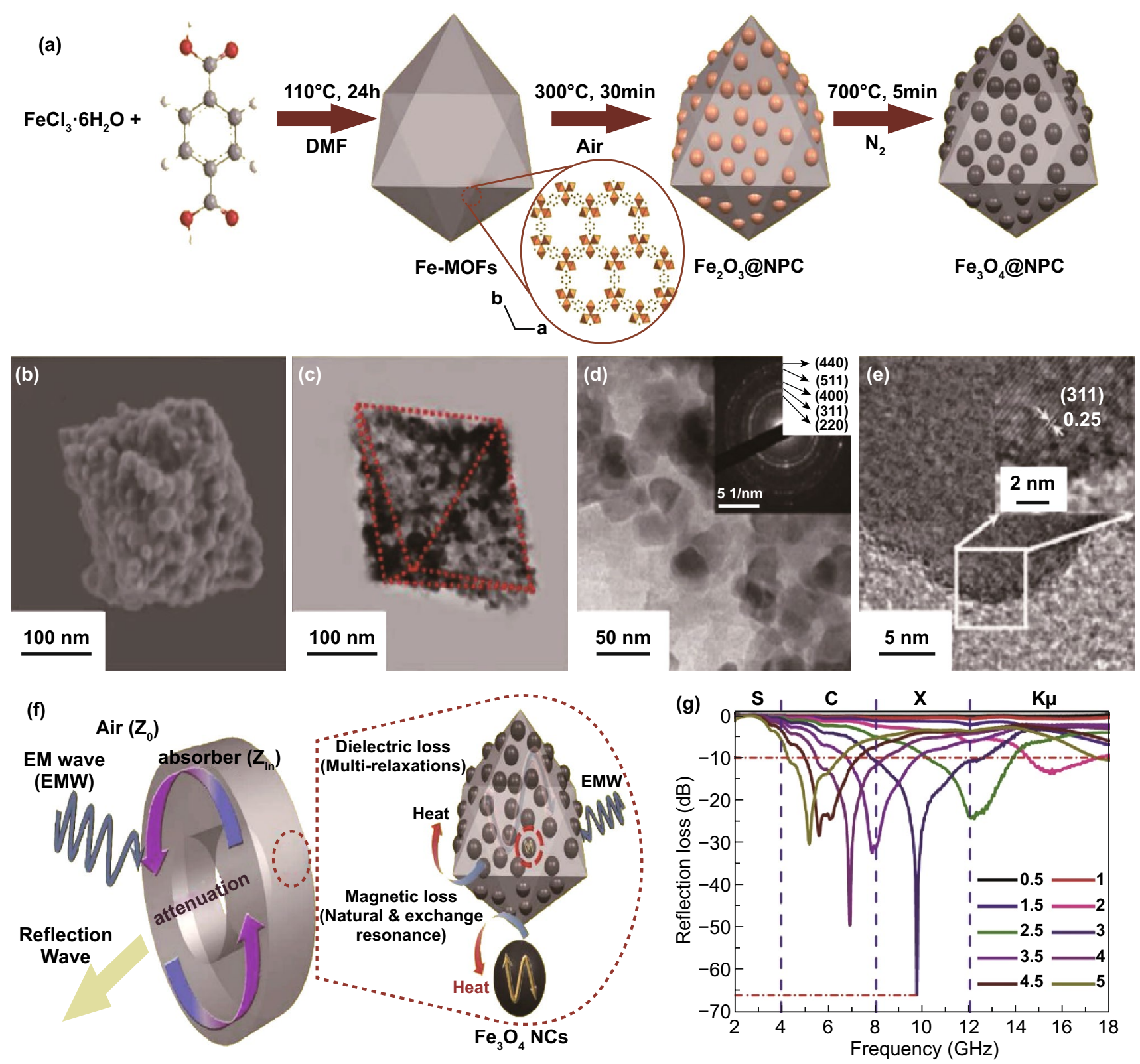

Fig. 8 a Schematic illustration of the $\mathrm{Fe}_{3} \mathrm{O}_{4} @$ NPC composites formation process. b-e SEM, low magnification TEM images, high magnification TEM images (inset: SAED patterns) and HRTEM images of $\mathrm{Fe}_{3} \mathrm{O}_{4} @$ NPC composites. $\mathrm{f}$ Schematic illustration of the electromagnetic wave absorption mechanism. g Electromagnetic wave reflection loss with various thicknesses for $\mathrm{Fe}_{3} \mathrm{O}_{4} @ \mathrm{NPC}$ composites. Reprinted with permission from Ref. [157] 


\subsection{Non-magnetic Single-Metal MOF-Derived PC-Based Nanocomposites as MAMs}

Non-magnetic single-metal MOF-derived PC-based nanocomposites usually act as dielectric performance but have negative characteristics in attenuation and impedance matching. Therefore, selecting a high dielectric candidate to combine with non-magnetic single-metal MOF or magnetic loss material is critical.

\subsubsection{Zn-MOF-Derived PC-Based Nanocomposites as MAMs}

Ji's group fabricated $\mathrm{ZnO} /$ nanoporous carbon (NPC)/ reduced graphene oxide (RGO) materials through a simple and valid hydrothermal method derived from $\mathrm{Zn}-\mathrm{MOF}$ [158]. The $R L_{\max }$ is $-50.5 \mathrm{~dB}$ with a thickness of $2.4 \mathrm{~mm}$, and the $E A B$ is $7.4 \mathrm{GHz}$ with a thickness of $2.6 \mathrm{~mm}$, which is shown in Fig. 9. The dielectric constant of $\mathrm{ZnO} / \mathrm{NPC} /$ RGO samples could be modulated by regulating the combination ratio. Too high or too low permittivity can hardly satisfy an ideal absorber. They had also prepared novel $\mathrm{ZnO} /$ carbon porous nanofibers derived from $\mathrm{Zn}-\mathrm{MOF}$ and polyacrylonitrile (PAN) nanofibers [159]. Xie reported polypyrrole (PPy)/Zn-MOF nanocomposites show tunable electrical conductivity as well as a tunable MA performance [160]. The EAB reaches $7.24 \mathrm{GHz}$ with the thickness of $2.6 \mathrm{~mm}$, and the $R L_{\max }$ is $-49 \mathrm{~dB}$ with the thickness of $2.9 \mathrm{~mm}$. The MA performance is attributed to the electrical conduction loss and interfacial polarization relaxation. (a)

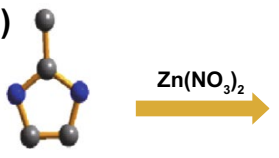

2-Methylimidazole

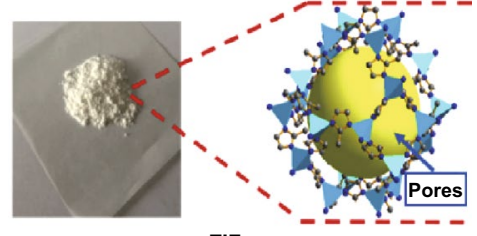

ZIFs

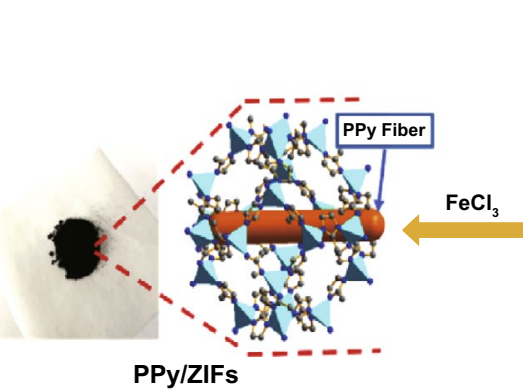

PPy/ZIFs

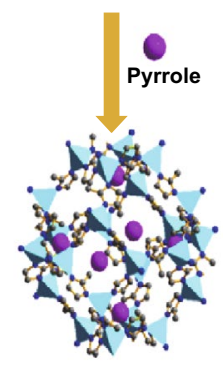

Pyrrole/ZIFs
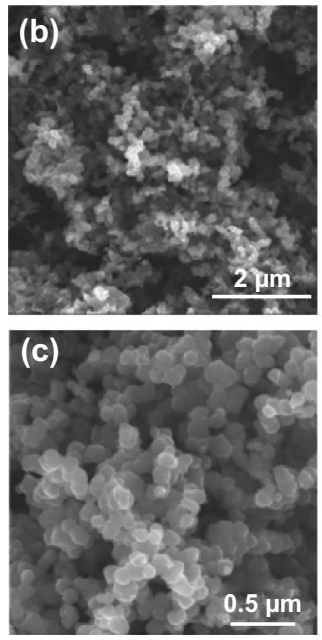
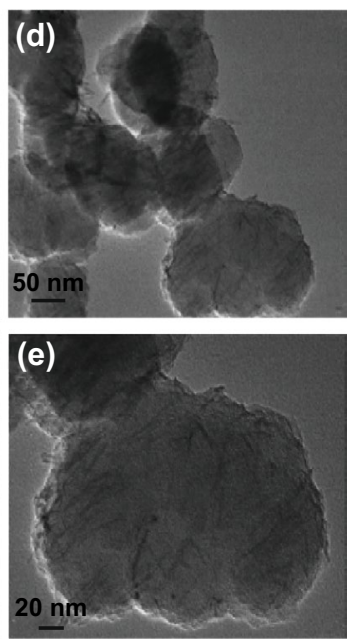

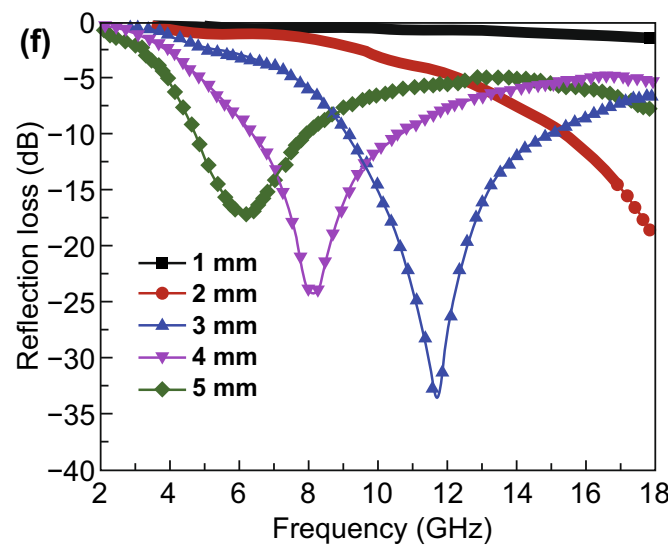

(g)

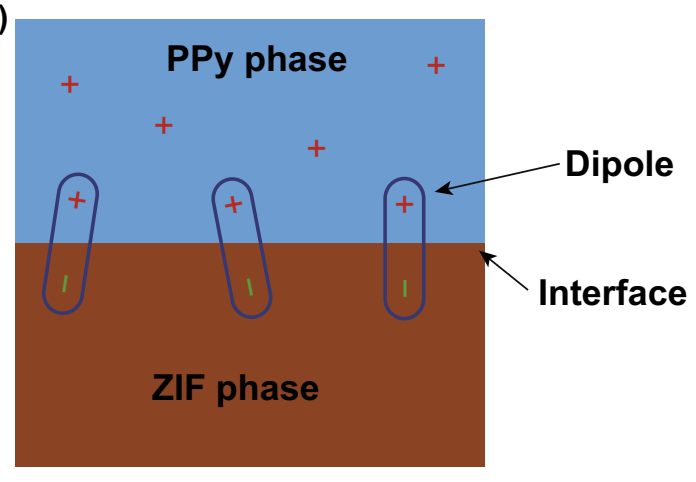

Fig. 9 a Preparation route of PPy/ZIFs nanocomposites. b, c SEM images, d, e TEM images and $\mathbf{f}$ MA performance of PPy/ZIFs. $\mathbf{g}$ Interfacial polarization of interfacial polarization. Reprinted with permission from Ref. [160] 


\subsubsection{Ti-MOF-Derived PC-Based Nanocomposites as MAMs}

Ji's group had also synthesized a novel nanoporous carbon material $\left(\mathrm{TiO}_{2} / \mathrm{C}\right)$ by annealing titanium-based MOFs (MIL-125 (Ti); MIL stands for Material from Institute Lavoisier) [161]. The $R L_{\max }$ is $-49.6 \mathrm{~dB}$, and the $\mathrm{EAB}$ is $4.6 \mathrm{GHz}(13.4-18 \mathrm{GHz})$ with the thickness of $1.6 \mathrm{~mm}$. The outstanding MA performance may be due to the high $\tan \delta_{\varepsilon}$, $\alpha$ and polarization loss.

\subsubsection{Cu-MOF-Derived PC-Based Nanocomposites as MAMs}

Zeng's group synthesized $\mathrm{Ni} / \mathrm{NiO} / \mathrm{Cu} @ \mathrm{C}$ composites by using $\mathrm{Cu}$ MOFs as the precursor [162]. The $R L_{\max }$ value is $-38.1 \mathrm{~dB}$ at a layer thickness of $3.2 \mathrm{~mm}$. The introduction of $\mathrm{Ni}$ offers magnetic loss, and interfacial polarization is changed by increasing the interface area and electrical conductivity.

\subsubsection{Zr-MOF-Derived PC-Based Nanocomposites as MAMs}

Liu's group developed cobalt-decorated porous $\mathrm{ZrO}_{2} / \mathrm{C}$ hybrid octahedrons by pyrolysis of $\mathrm{Co}\left(\mathrm{NO}_{3}\right)_{2}$ impregnated $\mathrm{NH}_{2}$-UIO-66(Zr-MOF) [44]. The sample results in $R L_{\max }$ of $-57.2 \mathrm{~dB}$ at $15.8 \mathrm{GHz}$, corresponding to a matching thickness of $3.3 \mathrm{~mm}$. The $E A B$ reaches $11.9 \mathrm{GHz}$ (6.1-18 GHz). The excellent MA performance of $\mathrm{Co} /$ $\mathrm{ZrO}_{2} / \mathrm{C}$ can be ascribed to the strong interface polarization and the suitable impedance matching, and the synergistic effect among the components. Wang had also synthesized $\mathrm{ZrO}_{2} / \mathrm{C}$ octahedra from UIO-66 [163]. The $R L_{\max }$ value of $-58.7 \mathrm{~dB}(16.8 \mathrm{GHz}, 1.5 \mathrm{~mm})$ has been achieved. And the EAB could cover $91.3 \%(3.4-18.0 \mathrm{GHz})$ of the measured frequency within the thickness range of $1.0-5.0 \mathrm{~mm}$.

\subsubsection{Rare-Earth MOF-Derived PC-Based Nanocomposites as MAMs}

Li's group had reported the synthesis of a series of rareearth MOFs based on MH (maleic hydrazide) ligands [13]. RE-MOFs have many advantages such as hierarchical porous structures, low density and large pore volume.
These properties will meet the requirements of MAMs. They successfully synthesized four novel RE-MOFs $\left[\mathrm{Y}_{2}(\mathrm{MH})_{6}\right]_{\mathrm{n}} \cdot \operatorname{DMF}(1),\left[\mathrm{Er}_{2}(\mathrm{MH})_{6}\right]_{\mathrm{n}}(2),\left[\mathrm{Yb}_{2}(\mathrm{MH})_{6}\right]_{\mathrm{n}}(3)$ and $\left[\mathrm{La}(\mathrm{MH})_{3}\right]_{\mathrm{n}}(4)$ by the traditional hydrothermal method. Different MA performances can be attributed to different structures and different central ions. The maximum $R L$ values of MOF 1, MOF 2, MOF 3 and MOF 4 are $-22.78 \mathrm{~dB}$ at $5 \mathrm{~mm}$, $-19.99 \mathrm{~dB}$ at $4.5 \mathrm{~mm},-28.14 \mathrm{~dB}$ at $2 \mathrm{~mm}$ and $-13.07 \mathrm{GHz}$ at $2 \mathrm{~mm}$, respectively. And the effective absorption bandwidth is $2.24 \mathrm{GHz}(6.8-9.04 \mathrm{GHz}), 2.12 \mathrm{GHz}$ (from 6.8 to $8.72 \mathrm{GHz}), 0.96 \mathrm{GHz}(15.76-16.72 \mathrm{GHz})$ and $0.32 \mathrm{GHz}$ (16.72-17.04 GHz) for MOF 1, MOF 2, MOF 3 and MOF 4. The property may be resulted in the synergetic effects of permittivity and permeability.

\subsection{Multi-metal MOF-Derived PC-Based Nanocomposites as MAMs}

The MA performance of multi-metal MOF-derived PCbased nanocomposite is often better than single-metal MOF because the multi-metal MOF combines the advantages of two or more materials, endows the mixture with new chemical and physical properties and effectively regulates the electromagnetic parameters of the MAMs.

\subsubsection{Multi-magnetic Metal MOF-Derived PC-Based Nanocomposites as MAMs}

NiCo nanoparticles/nanoporous carbon (NiCo/NPC) composites with multilayered structure were synthesized through in situ pyrolysis of the bimetallic NiCo-MOF by Lu's group [164]. The synergistic interactions of magnetic loss and dielectric loss among NiCo NPs, graphitized carbon layer and NPC were beneficial to the optimization of the impedance matching and the enhancement of EMW attenuation. The multilayered nanoporous carbon matrix leads to the multiple reflection and scatterings, interface and dipole polarization as well as the natural resonance and exchange resonance. The $R L_{\max }$ value is $-51 \mathrm{~dB}$ at $17.9 \mathrm{GHz}$ with $E A B$ of $4.5 \mathrm{GHz}(13.5-18 \mathrm{GHz})$ and a thickness of $1.5 \mathrm{~mm}$ at $600{ }^{\circ} \mathrm{C}$. Dong had also fabricated porous and hollow CoNi@C microspheres derived from CoNi-MOFs [165]. The $R L_{\max }$ can reach $-44.8 \mathrm{~dB}$ at $10.7 \mathrm{GHz}$, and the $E A B$ 
can reach up to $13.3 \mathrm{GHz}(4.7-18.0 \mathrm{GHz})$ with the thickness of 1.6-4.0 mm, as shown in Fig. 10. The simultaneous enhancement of attenuation ability and impedance matching together contribute to the improved MA performance. The attenuation ability comes from interfacial polarization, eddy current loss, multiple reflection and scattering. The impedance matching stems from magnetic CoNi alloy and dielectric graphitized carbon. Liu had also reported $\mathrm{CoNi} / \mathrm{C}$ nanocomposites derived from bimetallic CoNi-MOF [166]. The $R L_{\max }$ of $-74.7 \mathrm{~dB}$ could be achieved with a thickness of $1.8 \mathrm{~mm}$ at $15.6 \mathrm{GHz}$. The $E A B$ ranged from $2.9 \mathrm{GHz}$ to $18 \mathrm{GHz}$. The porous $\mathrm{Co}-\mathrm{Ni} / \mathrm{C}$ nanocomposites combined advantages of excellent impedance matching and strong interfacial loss between metallic NPs and porous carbon composites. Similarly, FeCo alloy/carbon composites [167] and $\mathrm{Fe}_{3} \mathrm{Ni} / \mathrm{C}$ composites [168] had also shown the excellent MA performance. Hollow sphere trimetallic FeCoNi@C MAMs via high-temperature carbonization were obtained using FeCoNi-based MOF-74 (FeCoNiMOF) as the precursor [169].

Other multi-magnetic metal MOF-derived PC-based nanocomposites as MAMs had also been reported. In order to further improve impedance matching, the dielectric loss is often introduced to the multi-magnetic metal MOF such as FeCo@C@CNGs(carbon nanocages) [170], NiCo alloy/carbon nanorod@CNT [171], Fe-Co/NC/rGO [172], FeNi@CNT/CNRs(carbon nanorods) [173] and $\mathrm{CoFe} @ \mathrm{C} @ \mathrm{MnO}_{2}$ [174]. All of these samples show good impedance matching and outstanding EMW attenuation capability. (a)
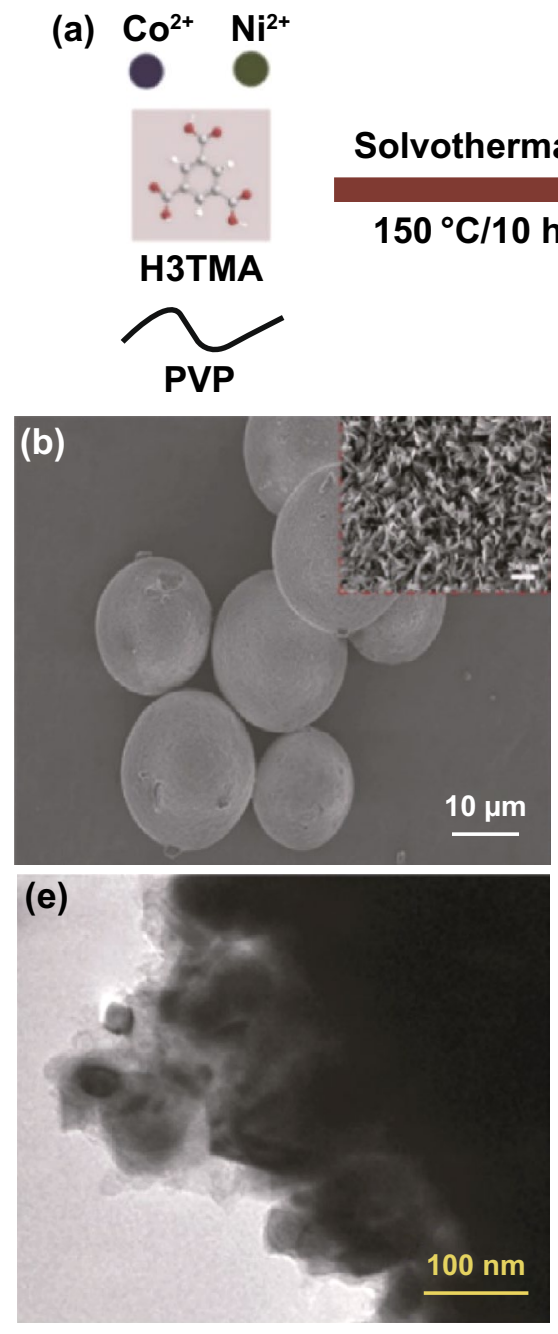

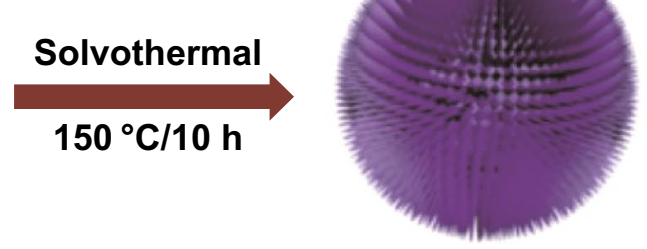

CoNi-MOFs
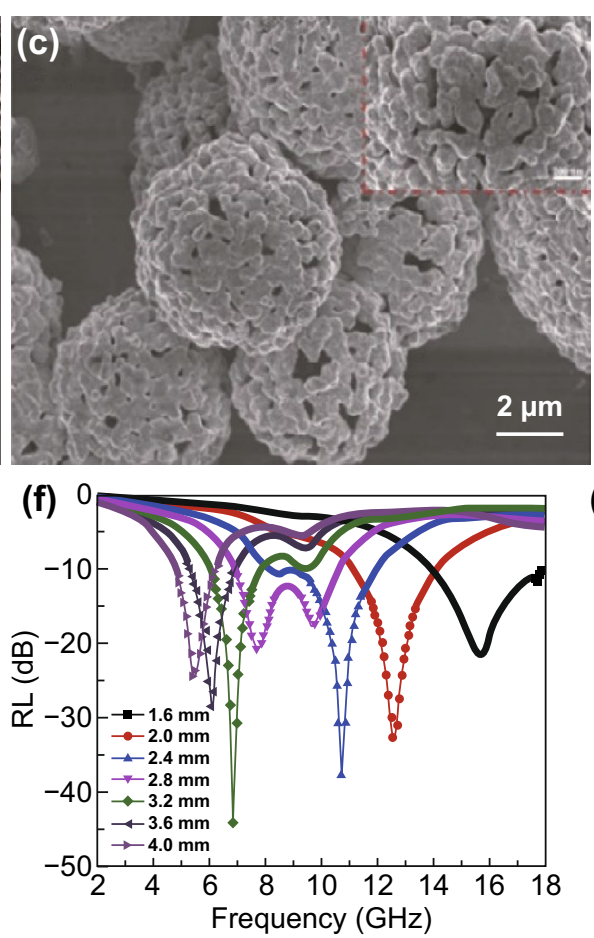

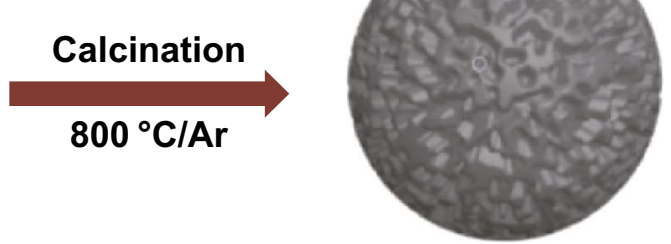

CNC composites

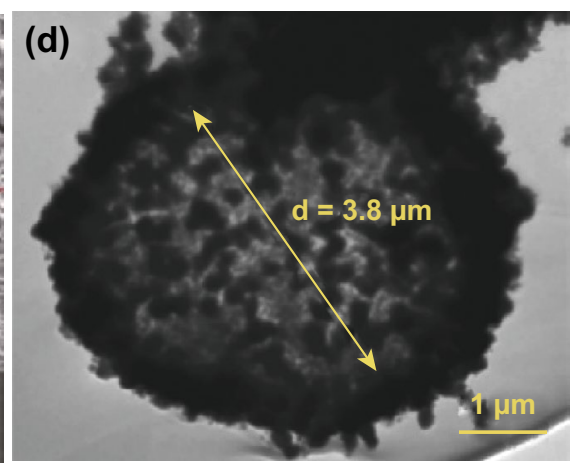

(g)

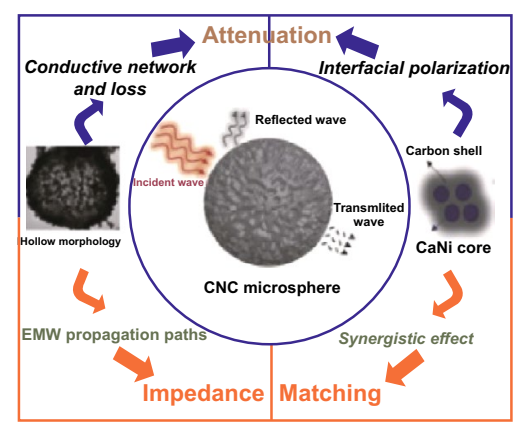

Fig. 10 a Illustration for the synthetic process of hollow CNC microspheres. b, c SEM images, $\mathbf{d}, \mathbf{e}$ TEM images and $\mathbf{f}$ RL curves of CoNi@C samples. g Schematic illustration of microwave absorption mechanisms for CNC microspheres. Reprinted with permission from Ref. [165] 


\subsubsection{Magnetic and Non-magnetic Metal MOF-Derived PC-Based Nanocomposites as MAMs}

Non-magnetic metal MOFs play the role of dielectric loss. $\mathrm{Zn}$ is most widely used in this occasion. Since the unique evaporation character of $\mathrm{Zn}$ metal under high pyrolysis temperature, the porous low-dielectric amorphous carbon/ $\mathrm{Zn}$ shell derived from $\mathrm{Zn}-\mathrm{MOF}$ was formed to decrease the permittivity for a better impedance match. Zheng's group fabricated nitrogen-doped $\mathrm{CoO} / \mathrm{Co} / \mathrm{C}$ nanocomposites by high-temperature pyrolysis of Co/Zn-ZIFs [175]. $\mathrm{Zn}$ was evaporated during the high-temperature pyrolysis process at $700{ }^{\circ} \mathrm{C}$. The $R L_{\max }$ reached $-66.7 \mathrm{~dB}$ at $7.2 \mathrm{GHz}$ with a thickness of $3.3 \mathrm{~mm}$, and the $E A B$ is $5.1 \mathrm{GHz}(12.6-17.7 \mathrm{GHz})$ with thickness of $1.8 \mathrm{~mm}$, as shown in Fig. 11. The excellent MA performance ascribed to the enhanced polarization relaxation, and synergistic effects of dielectric loss, conduction loss and magnetic loss.

Jiang had fabricated CoZn-MOF and then calcined it at different high temperatures to gain the metal Co embedded in porous and $\mathrm{N}$-doped graphitized carbon matrix (Co@pNGC) [176]. Zn species was also evaporated at high temperature. The $R L_{\max }$ is $-50.7 \mathrm{~dB}$ at $11.3 \mathrm{GHz}$, and the $E A B$ reaches $5.5 \mathrm{GHz}(12.3-17.8 \mathrm{GHz})$, corresponding to a thickness of $2.0 \mathrm{~mm}$. The strong dielectric loss is derived from interfacial polarization, migration, hopping of electrons and the magnetic loss from the Co nanoparticles.

\section{Comparison of MA Performance of Different MOF-Derived PC-Based Nanocomposites}

As is mentioned above, many MOF-derived PC-based nanocomposites exhibited the appreciable MA performance. In Table 2, we sum up the performance of the MAMs mentioned above. As is described, there are many kinds of MOF-derived PC-based materials used in the MAMs. Most of the MOF-derived PC-based MAMs have better MA performance than the comparison MAMs. The MA performance of pure $\mathrm{Ni}, \mathrm{Co}, \mathrm{Fe}-\mathrm{MOF}$-derived PC-based is not satisfactory. When they coupled with dielectric loss material, the MA performance will be significantly improved. Non-magnetic metal MOF-derived PC-based MAMs such as $\mathrm{Zn}, \mathrm{Ti}, \mathrm{Cu}, \mathrm{Zr}$ and $\mathrm{RE}$ are usually coupled with magnetic loss material to get impedance matching, while the multiple metal MOF-derived PC-based MAMs have shown excellent MA performance. They usually have multiple loss mechanism, so the synergistic effect between each part will be beneficial to impedance matching and electromagnetic wave attenuation. The structure of MOF also has a significant effect on the MA performance. Through design of MOF with different structures such as foam structure, core-shell structure, hollow structure, etc., the multiple reflections and interfacial polarization can be achieved. Therefore, MOF-derived PC-based nanocomposite is a promising material in the field of high-performance MAMs in the future.

\section{Conclusion}

The recent progress of MOF-derived PC-based nanocomposites as MAMs has been systematically summarized by this review. In view of these studies, we find that MOF-derived PC-based MAMs from in situ pyrolysis of MOFs will be a promising method for the development of lightweight and highly effective MAMs. After pyrolysis, the PC-based MAMs from the MOFs exhibit porosity, low density, good electrical conductivity and dielectric loss. And the inorganic metal center can result in magnetic loss (magnetic metal) or dielectric loss (non-magnetic metal). To further improve the MA performance, the MOF-derived PC-based nanocomposites often coupled with other loss material. The well-designed nanocomposites with multiple advantages will show good impedance matching and strong EM attenuation capability because of the multiple loss mechanism and synergistic effect of the multi-components. Therefore, the MOF-derived PCbased nanocomposites coupled with multiple loss material are an attractive development direction of MAMs in the future.

Many achievements have been made in MOF-derived PCbased nanocomposites as MAMs, but most are just at the research stage, far away from the practical use. The $E A B$ and the maximum $R L$ values are not enough to meet the actual needs. We can rationally design the MAMs with the suitable preparation conditions to realize the special microstructure, which can 
(a)
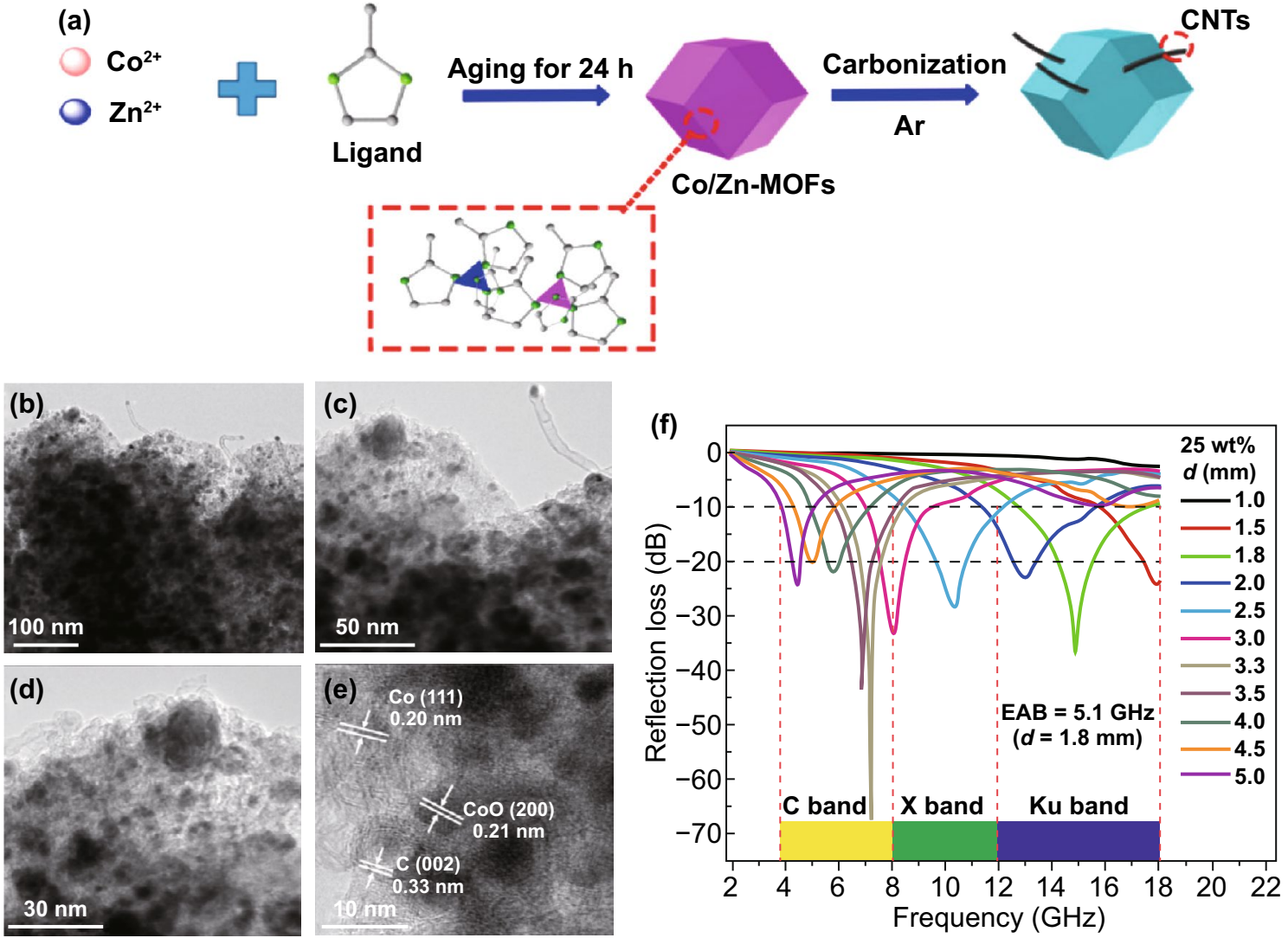

(g)

Reflected waves

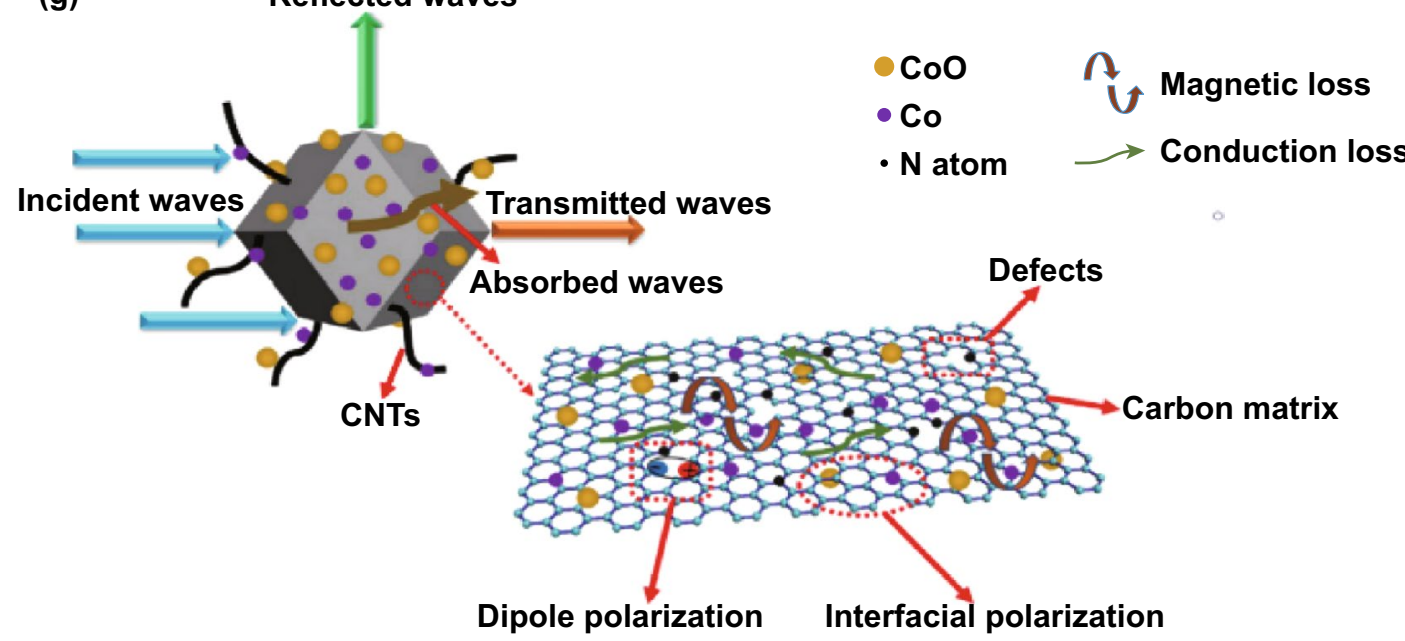

Fig. 11 a Schematic illustration of the preparation procedures of $\mathrm{CoO} / \mathrm{Co} / \mathrm{C}$ nanocomposites. b-e TEM images with different magnifications of $\mathrm{CoO} / \mathrm{Co} / \mathrm{C}$ nanocomposites. $\mathbf{f} \mathrm{RL}$ curves of $\mathrm{CoO} / \mathrm{Co} / \mathrm{C}$ nanocomposites. $\mathrm{g}$ Schematic illustration of the possible microwave absorption mechanisms of nitrogen-doped $\mathrm{CoO} / \mathrm{Co} / \mathrm{C}$ nanocomposites. Reprinted with permission from Ref. [175]

improve the scattering of EM, and the multiple loss mechanism is realized by the synergistic effect of multiple components. As more than 20,000 kinds of MOFs have been used in various fields, we only review the common $\mathrm{Ni}, \mathrm{Co}, \mathrm{Fe}, \mathrm{Zn}, \mathrm{Ti}, \mathrm{Cu}$,
$\mathrm{Zr}$ and RE metal as the central elements, and they have shown considerable MA performance. But they are just the tip of the iceberg of the big family of MOFs. We should also pay more attention to other metal elements. Through the modulation of 
Table 2 The MA performance of different kinds of MOF-derived PC-based nanocomposites as MAMs

\begin{tabular}{|c|c|c|c|c|c|c|c|}
\hline \multirow[t]{2}{*}{ Type } & \multirow[t]{2}{*}{ MAMs } & \multicolumn{3}{|l|}{$R L_{\max }$} & \multicolumn{2}{|c|}{$\mathrm{EAB}(<-10 \mathrm{~dB})(\mathrm{GHz})$} & \multirow[t]{2}{*}{ Refs. } \\
\hline & & Value (dB) & $f_{\mathrm{m}}(\mathrm{GHz})$ & Thickness (mm) & Value (GHz) & Thickness (mm) & \\
\hline \multirow{21}{*}{$\begin{array}{l}\text { MOF-derived PC-based } \\
\text { nanocomposites }\end{array}$} & $\mathrm{Co} / \mathrm{C}-500$ & -35.3 & 5.8 & 4 & $5.8(8.4-14.2)$ & 2.5 & [123] \\
\hline & $\mathrm{Co} / \mathrm{C}-650$ & -47.6 & 5.11 & 2 & $5.1(12.1-17.2)$ & 2 & [124] \\
\hline & $\mathrm{Co} / \mathrm{C}-700$ & -15.7 & 15.1 & 1.7 & $5.4(12.3-17.7)$ & 1.7 & [125] \\
\hline & $\mathrm{Co} / \mathrm{C}-700$ & -30.31 & 11.03 & 3 & $4.93(8.31-13.24)$ & 3 & [126] \\
\hline & $\mathrm{Co} / \mathrm{C}-800$ & -39.6 & 9.6 & 2 & $3.8(10.7-14.5)$ & 2 & [127] \\
\hline & MOF/RGO-500 & -52 & 9.6 & 4.1 & $7.72(10.28-18)$ & 3.2 & [128] \\
\hline & CoC-rGO-2 & -44.77 & 12.1 & 2.1 & $5.2(12.8-18)$ & 1.8 & [129] \\
\hline & $\mathrm{Co}_{3} \mathrm{O}_{4} / \mathrm{Co} / \mathrm{RGO}$ & -52.8 & 13.12 & 2 & $10.72(4.88-15.6)$ & $2-4$ & [130] \\
\hline & 3D Co/C-MCNT & -20.3 & 13.84 & 1.8 & 4.08 & 1.8 & [131] \\
\hline & $\mathrm{Co} / \mathrm{C}-\mathrm{MCNTs}$ & -48.9 & 9 & 2.99 & - & - & [132] \\
\hline & $\mathrm{Co} / \mathrm{CNT}$ & -49.16 & 14.16 & 2.5 & $4.2(12.4-16.6)$ & 2.5 & [133] \\
\hline & $\begin{array}{l}\text { MWCNTs@ carbona- } \\
\text { ceous CoO }\end{array}$ & -50.2 & 14.3 & 1.84 & $4.32(12.32-16.64)$ & 1.84 & [134] \\
\hline & $\begin{array}{l}\text { CNFs@ carbonaceous } \\
\text { Co/CoO }\end{array}$ & -53.1 & 6.56 & 3.54 & $\begin{array}{l}13.52(3.68-14.64, \\
15.44-18)\end{array}$ & $2-5$ & [135] \\
\hline & Co/C@PPy & -44.76 & 17.32 & 2.0 & $6.56(11.04-17.60)$ & 2.5 & [136] \\
\hline & Co/NPC@ZnO/rGO & -45.4 & 14.2 & 2 & $5.4(11.9-17.3)$ & 2 & [138] \\
\hline & $\mathrm{Co} / \mathrm{C} @ \mathrm{~V}_{2} \mathrm{O}_{3}$ & -40.1 & 14.1 & 1.5 & $4.64(13.36-18)$ & 1.5 & [139] \\
\hline & $\mathrm{MnO} @ \mathrm{Co} / \mathrm{C}$ & -49.06 & 6.48 & 3.4 & 2.24 & 3.4 & [140] \\
\hline & $\mathrm{Co} / \mathrm{N} / \mathrm{C} @ \mathrm{MnO}_{2}$ & -58.9 & 5.56 & 3.7 & 5.5 & - & [141] \\
\hline & NRGO/MWCNT & -69.6 & 12.5 & 1.8 & $4.3(13.2-17.5)$ & 1.5 & [143] \\
\hline & $\mathrm{Co} / \mathrm{CNTs} / \mathrm{CS}$ & -51.2 & 12 & 2.2 & $4.1(10.3-14.4)$ & 2.2 & [144] \\
\hline & $\mathrm{Co} / \mathrm{C}-\mathrm{HS}$ & -66.5 & 17.6 & 1.53 & $14.3(3.7-18.0)$ & $1-5$ & [145] \\
\hline \multirow{6}{*}{$\begin{array}{l}\text { Ni-MOF-derived PC- } \\
\text { based nanocomposites }\end{array}$} & Ni@C-800 & -57 & 13.8 & 1.85 & $6(12-18)$ & $1-5$ & [146] \\
\hline & $\mathrm{NPC} / \mathrm{Ni}$ & -39.4 & - & - & 4.2 & - & [147] \\
\hline & Ni@C-ZIF & -86.8 & 7.25 & 2.7 & $7.4(4-11.4)$ & $1.5-4$ & [149] \\
\hline & $\mathrm{SiC} / \mathrm{Ni} / \mathrm{NiO} / \mathrm{C}$ & -50.52 & 13 & 4 & $2.96(14.76-17.72)$ & 2.5 & [150] \\
\hline & $\begin{array}{l}\text { NiO/Ni/GN@Air@NiO/ } \\
\text { Ni/GN }\end{array}$ & -34.5 & 17.2 & 1.7 & $10.2(7.8-18)$ & $1.7-5.0$ & [151] \\
\hline & Porous flower-like $\mathrm{Ni} / \mathrm{C}$ & -52.4 & 16.1 & 1.6 & 5 & 1.6 & [152] \\
\hline \multirow{5}{*}{$\begin{array}{l}\text { Fe-MOF-derived PC- } \\
\text { based nanocomposites }\end{array}$} & $\mathrm{Fe} / \mathrm{C}$ nanocubes & -22.6 & 4 & 5 & $7.2(10.8-18)$ & 2 & [153] \\
\hline & FC-650 & -39.43 & 14 & 2 & $5.36(11.76-17.12)$ & 2 & [154] \\
\hline & Fe/C-700-101 & -59.2 & 5 & 4.32 & 5 & 1.8 & [155] \\
\hline & $\mathrm{MOF}(\mathrm{Fe}) / \mathrm{PANI}$ & -41.4 & 11.6 & 2 & $5.5(9.8-15.3)$ & 2 & [156] \\
\hline & $\mathrm{Fe}_{3} \mathrm{O}_{4} @ \mathrm{NPC}$ & -65.5 & 9.8 & 3 & 4.5 & 3 & [157] \\
\hline \multirow{3}{*}{$\begin{array}{l}\text { Zn-MOF-derived PC- } \\
\text { based nanocomposites }\end{array}$} & $\mathrm{ZnO} / \mathrm{NPC} / \mathrm{RGO}$ & -50.5 & 14 & 2.4 & $7.4(9.6-17)$ & 2.6 & [158] \\
\hline & $\mathrm{Fe}_{3} \mathrm{O}_{4} / \mathrm{CNT}$ & -43 & 15.2 & 1.5 & $8.3(9.7-18)$ & 1.75 & [159] \\
\hline & PPy/ZIFs & -49 & 12.1 & 2.9 & $7.24(10.76-18)$ & 2.6 & [160] \\
\hline $\begin{array}{l}\text { Ti-MOF-derived PC- } \\
\text { based nanocomposites }\end{array}$ & $\mathrm{TiO}_{2} / \mathrm{C}$ & -49.6 & 15.8 & 1.6 & $4.6(13.4-18 \mathrm{GHz})$ & 1.6 & [161] \\
\hline $\begin{array}{l}\text { Cu-MOF-derived PC- } \\
\text { based nanocomposites }\end{array}$ & Ni/NiO/Cu@C & -38.1 & 14.8 & 3.2 & - & - & [162] \\
\hline $\begin{array}{l}\text { Zr-MOF-derived PC- } \\
\text { based nanocomposites }\end{array}$ & $\mathrm{ZrO}_{2} / \mathrm{C}$ & -57.2 & 15.8 & 3.3 & $11.9(6.1-18)$ & 3.3 & [44] \\
\hline
\end{tabular}


Table 2 (continued)

\begin{tabular}{|c|c|c|c|c|c|c|c|}
\hline \multirow[t]{2}{*}{ Type } & \multirow[t]{2}{*}{ MAMs } & \multicolumn{3}{|l|}{$R L_{\max }$} & \multicolumn{2}{|c|}{$\mathrm{EAB}(<-10 \mathrm{~dB})(\mathrm{GHz})$} & \multirow[t]{2}{*}{ Refs. } \\
\hline & & Value $(\mathrm{dB})$ & $f_{\mathrm{m}}(\mathrm{GHz})$ & Thickness (mm) & Value $(\mathrm{GHz})$ & Thickness (mm) & \\
\hline & $\mathrm{ZrO}_{2} / \mathrm{C}$ & -58.7 & 16.8 & 1.5 & $14.6(3.4-18.0)$ & $1-5$ & [163] \\
\hline \multirow{2}{*}{$\begin{array}{l}\text { RE-MOF-derived PC- } \\
\text { based nanocomposites }\end{array}$} & {$\left[\mathrm{Yb}_{2}(\mathrm{MH})_{6}\right]_{\mathrm{n}}$} & -28.14 & - & 2 & - & - & [13] \\
\hline & {$\left[\mathrm{Y}_{2}(\mathrm{MH})_{6}\right]_{\mathrm{n}} \cdot \mathrm{DMF}$} & - & - & - & $2.24(6.8-9.04)$ & 5 & \\
\hline \multirow{11}{*}{$\begin{array}{l}\text { Multi-magnetic metal } \\
\text { MOF-derived PC- } \\
\text { based nanocomposites }\end{array}$} & $\mathrm{NiCo} / \mathrm{NPC}$ & -51 & 17.9 & 1.5 & $4.5(13.5-18)$ & 1.5 & [164] \\
\hline & CoNi@C & -44.8 & 6.8 & 3.2 & $13.3(4.7-18.0)$ & $1.6-4$ & [165] \\
\hline & $\mathrm{CoNi} / \mathrm{C}$ & -74.7 & 15.6 & 1.8 & $15.1(2.9-18.0)$ & $0.3-5$ & [166] \\
\hline & FeCo alloy/carbon & -57.4 & 17.7 & 1.26 & $4.2(11.0-15.2)$ & - & [167] \\
\hline & $\mathrm{Fe}_{3} \mathrm{Ni} / \mathrm{C}$ & -46.2 & 10.44 & 2.65 & $5.24(12.76-18)$ & 2 & [168] \\
\hline & FeCoNi@C & -69.03 & 5.52 & 2.1 & $8.08(9.92-18)$ & 2.47 & [169] \\
\hline & $\begin{array}{l}\text { Core-shell FeCo@ } \\
\text { carbon/PDA }\end{array}$ & -67.8 & 15.8 & 1.75 & $5.3(11.0-16.3)$ & 2 & [170] \\
\hline & $\begin{array}{l}\text { NiCo alloy/C nanorod@ } \\
\text { CNT }\end{array}$ & -58.8 & 14.0 & 2.2 & $6.5(11.5-18)$ & 2.2 & [171] \\
\hline & $\mathrm{Fe}-\mathrm{Co} / \mathrm{NC} / \mathrm{rGO}$ & -43.26 & 11.28 & 2.5 & $9.12(8.88-18)$ & 2.63 & [172] \\
\hline & FeNi@CNT/CNRs & -47.0 & - & 2.3 & 4.5 & 1.6 & [173] \\
\hline & $\begin{array}{l}\mathrm{CoFe} @ \mathrm{C} @ \mathrm{MnO}_{2} \\
\text { nanocubes }\end{array}$ & -64 & 15.6 & 1.3 & $9.2(8.8-18)$ & 1.6 & [174] \\
\hline \multirow{2}{*}{$\begin{array}{l}\text { Magnetic and non- } \\
\text { magnetic metal MOF- } \\
\text { derived PC-based } \\
\text { nanocomposites }\end{array}$} & $\mathrm{CoO} / \mathrm{Co} / \mathrm{C}$ & -66.7 & 7.2 & 3.3 & $5.1(12.6-17.7)$ & 1.8 & {$[175]$} \\
\hline & Co@pNGC & -50.7 & 11.3 & 2.5 & $4.0(12.2-16.2)$ & 1.2 & [176] \\
\hline \multirow[t]{13}{*}{ Comparison MAMs } & $\mathrm{CNT}$ & -21 & 5 & 3.5 & 0.5 & 3.5 & [177] \\
\hline & rGO & -6.9 & 7 & 2 & - & - & [178] \\
\hline & graphene foam & -34 & 13.1 & - & $14.3(3.7-18)$ & - & [59] \\
\hline & $\begin{array}{l}\text { Carbon nanotube/gra- } \\
\text { phene foams }\end{array}$ & -39.5 & 11.6 & - & 16 & - & [179] \\
\hline & $\begin{array}{l}\text { Carbon nanotube grown } \\
\text { on the carbon fiber }\end{array}$ & -42 & 11.4 & 2.5 & 2.7 & 2.5 & [180] \\
\hline & 3D PPy aerogel & -22.5 & 12 & 3 & $5.0(10.0-15.0)$ & 3 & [181] \\
\hline & PANI nanoparticle & -18.8 & 17.2 & 2 & $3.9(14.1-18.0)$ & 2 & [182] \\
\hline & $\mathrm{ZnO}$ nanoparticles & -37.7 & 8.96 & 2.1 & $3.55(7.5-11.05)$ & 2.1 & [183] \\
\hline & $\mathrm{C}_{3} \mathrm{~N}_{4}$ nanosheets & -36.1 & 14.6 & 19.5 & 1.7 & 19.5 & [184] \\
\hline & $\mathrm{SiC}$ & -24.8 & 11 & 3 & $4.2(8.2-12.4)$ & 3 & [185] \\
\hline & Fe powder & -5.2 & 11 & 3 & - & - & [186] \\
\hline & $\mathrm{Fe}_{3} \mathrm{O}_{4} @ \mathrm{C}$ & -40 & 15.9 & 1.5 & $3.9(14.1-18)$ & 1.5 & [93] \\
\hline & $\begin{array}{l}\text { Flaky carbonyl iron } \\
\text { particles }\end{array}$ & -14 & 0.6 & 1 & $1.6(0.4-2)$ & 1 & [187] \\
\hline
\end{tabular}

inorganic metal center and organic ligand, different kinds of MOFs are constructed to achieve the optimal MA performance. The "thin, wide, light, strong" is the goal to develop MAMs, but most of the studies merely focus on the EAB and the maximum $R L$ values, while the thickness and the weight of the MAMs have been usually ignored. In fact, low density is also an important parameter to evaluate the MAMs. One of the pyrolysis products of MOFs is carbon; therefore, MOFs are promising materials to employ new lightweight MAMs, especially in military applications. In conclusion, MOF-derived PC-based nanocomposites 
had already shown its great potential as MAMs. We firmly believe that the MOF-derived PC-based nanocomposites will be widely used in the field of MAMs in the future.

Acknowledgements The authors gratefully acknowledge financial support from Ministry of Science and Technology of China (MoST, 2016YFA0200200), the National Natural Science Foundation of China (NSFC, 21875114, 51373078, and 51422304) and NSF of Tianjin City (15JCYBJC17700).

Open Access This article is licensed under a Creative Commons Attribution 4.0 International License, which permits use, sharing, adaptation, distribution and reproduction in any medium or format, as long as you give appropriate credit to the original author(s) and the source, provide a link to the Creative Commons licence, and indicate if changes were made. The images or other third party material in this article are included in the article's Creative Commons licence, unless indicated otherwise in a credit line to the material. If material is not included in the article's Creative Commons licence and your intended use is not permitted by statutory regulation or exceeds the permitted use, you will need to obtain permission directly from the copyright holder. To view a copy of this licence, visit http://creativecommons.org/licenses/by/4.0/.

\section{References}

1. N. Wu, D. Xu, Z. Wang, F. Wang, J. Liu et al., Achieving superior electromagnetic wave absorbers through the novel metal-organic frameworks derived magnetic porous carbon nanorods. Carbon 145, 433-444 (2019). https://doi. org/10.1016/j.carbon.2019.01.028

2. H. Lv, X. Liang, G. Ji, H. Zhang, Y. Du, Porous three-dimensional flower-like $\mathrm{Co} / \mathrm{CoO}$ and its excellent electromagnetic absorption properties. ACS Appl. Mater. Interfaces. 7(18), 9776-9783 (2015). https://doi.org/10.1021/acsami.5b01654

3. S. Xie, Z. Ji, L. Zhu, J. Zhang, Y. Cao et al., Recent progress in electromagnetic wave absorption building materials. J. Build. Eng. 27, 100963 (2020). https://doi.org/10.1016/j. jobe.2019.100963

4. L. Heng, Z. Zhang, X. Chen, S. Wang, Z. Wu et al., Fe/nanoporous carbon hybrid derived from metal-organic framework for highly effective microwave absorption. Appl. Organomet. Chem. 33(8), e4991 (2019). https://doi.org/10.1002/aoc.4991

5. S.U. Rehman, J. Wang, Q. Luo, M. Sun, L. Jiang et al., Starfish-like $\mathrm{C} / \mathrm{CoNiO}_{2}$ heterostructure derived from $\mathrm{ZIF}$ 67 with tunable microwave absorption properties. Chem. Eng. J. 373, 122-130 (2019). https://doi.org/10.1016/j. cej.2019.05.040

6. M. Qiao, X. Lei, Y. Ma, L. Tian, X. He et al., Application of yolk-shell $\mathrm{Fe}_{3} \mathrm{O}_{4} @ \mathrm{~N}$-doped carbon nanochains as highly effective microwave-absorption material. Nano Res. 11(3), 1500-1519 (2018). https://doi.org/10.1007/s1227 4-017-1767-0

7. B. Shen, W. Zhai, M. Tao, J. Ling, W. Zheng, Lightweight, multifunctional polyetherimide/graphene@ $\mathrm{Fe}_{3} \mathrm{O}_{4}$ composite foams for shielding of electromagnetic pollution. ACS Appl.
Mater. Interfaces. 5(21), 11383-11391 (2013). https://doi. org/10.1021/am4036527

8. J.L. Liu, H.S. Liang, Y. Zhang, G.L. Wu, H.J. Wu, Facile synthesis of ellipsoid-like $\mathrm{MgCo}_{2} \mathrm{O}_{4} / \mathrm{Co}_{3} \mathrm{O}_{4}$ composites for strong wideband microwave absorption application. Compos. Part B Eng. 176, 12 (2019). https://doi.org/10.1016/j.compo sitesb.2019.107240

9. X.F. Zhou, Z.R. Jia, A.L. Feng, X.X. Wang, J.J. Liu et al., Synthesis of fish skin-derived 3D carbon foams with broadened bandwidth and excellent electromagnetic wave absorption performance. Carbon 152, 827-836 (2019). https://doi. org/10.1016/j.carbon.2019.06.080

10. P. Liu, Y. Huang, J. Yan, Y. Yang, Y. Zhao, Construction of $\mathrm{CuS}$ nanoflakes vertically aligned on magnetically decorated graphene and their enhanced microwave absorption properties. ACS Appl. Mater. Interfaces. 8(8), 5536-5546 (2016). https://doi.org/10.1021/acsami.5b10511

11. M.-M. Lu, M.-S. Cao, Y.-H. Chen, W.-Q. Cao, J. Liu et al., Multiscale assembly of grape-like ferroferric oxide and carbon nanotubes: a smart absorber prototype varying temperature to tune intensities. ACS Appl. Mater. Interfaces. 7(34), 19408-19415 (2015). https://doi.org/10.1021/acsami.5b055 95

12. D. Ding, Y. Wang, X. Li, R. Qiang, P. Xu et al., Rational design of core-shell Co@C microspheres for high-performance microwave absorption. Carbon 111, 722-732 (2017). https://doi.org/10.1016/j.carbon.2016.10.059

13. L.W. Zhu, N. Liu, X.H. Jiang, L.M. Yu, X. Li, Four novel 3D RE-MOFs based on maleic hydrazide: syntheses, structural diversity, efficient electromagnetic wave absorption and antibacterial activity properties. Inorg. Chim. Acta 501, 119291 (2020). https://doi.org/10.1016/j.ica.2019.119291

14. Y. Zhang, X. Wang, M. Cao, Confinedly implanted $\mathrm{NiFe}_{2} \mathrm{O}_{4}$-rGO: cluster tailoring and highly tunable electromagnetic properties for selective-frequency microwave absorption. Nano Res. 11(3), 1426-1436 (2018). https://doi. org/10.1007/s12274-017-1758-1

15. P. Saini, M. Arora, G. Gupta, B.K. Gupta, V.N. Singh et al., High permittivity polyaniline-barium titanate nanocomposites with excellent electromagnetic interference shielding response. Nanoscale 5(10), 4330-4336 (2013). https://doi. org/10.1039/c3nr00634d

16. L. Huang, J. Li, Z. Wang, Y. Li, X. He et al., Microwave absorption enhancement of porous $\mathrm{C} @ \mathrm{CoFe}_{2} \mathrm{O}_{4}$ nanocomposites derived from eggshell membrane. Carbon 143, 507516 (2019). https://doi.org/10.1016/j.carbon.2018.11.042

17. Z. Xu, Y. Du, D. Liu, Y. Wang, W. Ma et al., Pea-like Fe/Fe ${ }_{3} \mathrm{C}$ nanoparticles embedded in nitrogen-doped carbon nanotubes with tunable dielectric/magnetic loss and efficient electromagnetic absorption. ACS Appl. Mater. Interfaces. 11(4), 4268-4277 (2019). https://doi.org/10.1021/acsami.8b19201

18. X.-X. Wang, T. Ma, J.-C. Shu, M.-S. Cao, Confinedly tailoring $\mathrm{Fe}_{3} \mathrm{O}_{4}$ clusters-NG to tune electromagnetic parameters and microwave absorption with broadened bandwidth. Chem. Eng. J. 332, 321-330 (2018). https://doi.org/10.1016/j. cej.2017.09.101 
19. Z. Jia, D. Lan, K. Lin, M. Qin, K. Kou et al., Progress in low-frequency microwave absorbing materials. J. Mater. Sci.: Mater. Electron. 29(20), 17122-17136 (2018). https://doi. org/10.1007/s10854-018-9909-Z

20. H. Zhao, Y. Cheng, W. Liu, L. Yang, B. Zhang et al., Biomass-derived porous carbon-based nanostructures for microwave absorption. Nano-Micro Lett. 11(1), 24 (2019). https:// doi.org/10.1007/s40820-019-0255-3

21. H. Zhao, Y. Cheng, H. Lv, G. Ji, Y. Du, A novel hierarchically porous magnetic carbon derived from biomass for strong lightweight microwave absorption. Carbon 142, 245-253 (2019). https://doi.org/10.1016/j.carbon.2018.10.027

22. S. Ghosh, S. Remanan, S. Mondal, S. Ganguly, P. Das et al., An approach to prepare mechanically robust full IPN strengthened conductive cotton fabric for high strain tolerant electromagnetic interference shielding. Chem. Eng. J. 344, 138-154 (2018). https://doi.org/10.1016/j. cej.2018.03.039

23. K. Srogi, Microwave-assisted sample preparation of coal and coal fly ash for subsequent metal determination. Anal. Lett. 40(2), 199-232 (2007). https://doi.org/10.1080/0003271060 0867713

24. X. Zhang, J. Qiao, F. Wang, L. Lv, D. Xu et al., Tailoring electromagnetic absorption performances of $\mathrm{TiO}_{2} / \mathrm{Co} /$ carbon nanofibers through tuning graphitization degrees. Ceram. Int. 46(4), 4754-4761 (2020). https://doi.org/10.1016/j.ceram int.2019.10.207

25. B. Zhao, G. Shao, B. Fan, W. Zhao, Y. Xie et al., Synthesis of flower-like $\mathrm{CuS}$ hollow microspheres based on nanoflakes self-assembly and their microwave absorption properties. J. Mater. Chem. A 3(19), 10345-10352 (2015). https://doi. org/10.1039/c5ta00086f

26. A. Munir, Microwave radar absorbing properties of multiwalled carbon nanotubes polymer composites: a review. Adv. Polym. Tech. 36(3), 362-370 (2017). https://doi.org/10.1002/ adv. 21617

27. M. Safaei, M.M. Foroughi, N. Ebrahimpoor, S. Jahani, A. Omidi et al., A review on metal-organic frameworks: synthesis and applications. Trac-Trends Anal. Chem. 118, 401-425 (2019). https://doi.org/10.1016/j.trac.2019.06.007

28. X. Xu, F. Ran, Z. Fan, H. Lai, Z. Cheng et al., Cactus-inspired bimetallic metal-organic framework-derived 1D-2D hierarchical $\mathrm{Co} / \mathrm{N}$-decorated carbon architecture toward enhanced electromagnetic wave absorbing performance. ACS Appl. Mater. Interfaces. 11(14), 13564-13573 (2019). https://doi. org/10.1021/acsami.9b00356

29. Y. Wang, X. Gao, C. Lin, L. Shi, X. Li et al., Metal organic frameworks-derived Fe-Co nanoporous carbon/graphene composite as a high-performance electromagnetic wave absorber. J. Alloys Compd. 785, 765-773 (2019). https://doi. org/10.1016/j.jallcom.2019.01.271

30. Y. Ye, Z. Ma, R.-B. Lin, R. Krishna, W. Zhou et al., Pore space partition within a metal-organic framework for highly efficient $\mathrm{C}_{2} \mathrm{H}_{2} / \mathrm{CO}_{2}$ separation. J. Am. Chem. Soc. 141(9), 4130-4136 (2019). https://doi.org/10.1021/jacs.9b00232
31. H. Zhang, X. Liu, Y. Wu, C. Guan, A.K. Cheetham et al., MOF-derived nanohybrids for electrocatalysis and energy storage: current status and perspectives. Chem. Commun. 54(42), 5268-5288 (2018). https://doi.org/10.1039/c8cc0 $0789 \mathrm{f}$

32. Z.-X. Cai, Z.-L. Wang, J. Kim, Y. Yamauchi, Hollow functional materials derived from metal-organic frameworks: synthetic strategies, conversion mechanisms, and electrochemical applications. Adv. Mater. 31(11), 1804903 (2019). https://doi.org/10.1002/adma.201804903

33. Z. Liang, C. Qu, W. Guo, R. Zou, Q. Xu, Pristine metalorganic frameworks and their composites for energy storage and conversion. Adv. Mater. (2018). https://doi.org/10.1002/ adma.201702891

34. X. Wei, Y. Li, H. Peng, M. Zhou, Y. Ou et al., Metal-organic framework-derived hollow $\mathrm{CoS}$ nanobox for high performance electrochemical energy storage. Chem. Eng. J. 341, 618-627 (2018). https://doi.org/10.1016/j.cej.2018.02.032

35. J. Li, W. Huang, M. Wang, S. Xi, J. Meng et al., Low-crystalline bimetallic metal-organic framework electrocatalysts with rich active sites for oxygen evolution. ACS Energy Lett. 4(1), 285-292 (2019). https://doi.org/10.1021/acsenergylett.8b023 45

36. B. Zhu, R. Zou, Q. Xu, Metal-organic framework based catalysts for hydrogen evolution. Adv. Energy Mater. (2018). https://doi.org/10.1002/aenm.201801193

37. R.-B. Lin, S. Xiang, H. Xing, W. Zhou, B. Chen, Exploration of porous metal-organic frameworks for gas separation and purification. Coord. Chem. Rev. 378, 87-103 (2019). https:// doi.org/10.1016/j.ccr.2017.09.027

38. X. Jiang, S. Li, Y. Bai, L. Shao, Ultra-facile aqueous synthesis of nanoporous zeolitic imidazolate framework membranes for hydrogen purification and olefin/paraffin separation. J. Mater. Chem. A 7(18), 10898-10904 (2019). https://doi. org/10.1039/c8ta11748a

39. J. Chang, X. Wang, J. Wang, H. Li, F. Li, Nucleic acidfunctionalized metal-organic framework-based homogeneous electrochemical biosensor for simultaneous detection of multiple tumor biomarkers. Anal. Chem. 91(5), 3604-3610 (2019). https://doi.org/10.1021/acs.analchem.8b05599

40. Y. Li, M. Xie, X. Zhang, Q. Liu, D. Lin, C. Xu, F. Xie, X. Sun, Co-MOF nanosheet array: a high-performance electrochemical sensor for non-enzymatic glucose detection. Sens. Actuat. B Chem. 278, 126-132 (2019). https://doi. org/10.1016/j.snb.2018.09.076

41. W. Liu, S. Tan, Z. Yang, G. Ji, Enhanced low-frequency electromagnetic properties of MOF-derived cobalt through interface design. ACS Appl. Mater. Interfaces. 10(37), 31610 31622 (2018). https://doi.org/10.1021/acsami.8b10685

42. H. Xu, X. Yin, M. Zhu, M. Li, H. Zhang et al., Constructing hollow graphene nano-spheres confined in porous amorphous carbon particles for achieving full $\mathrm{X}$ band microwave absorption. Carbon 142, 346-353 (2019). https://doi.org/10.1016/j. carbon.2018.10.056

43. Y. Zhang, S. Gao, H. Xing, H. Li, In situ carbon nanotubes encapsulated metal Nickel as high-performance microwave 
absorber from Ni-Zn metal-organic framework derivative. J. Alloys Compd. 801, 609-618 (2019). https://doi. org/10.1016/j.jallcom.2019.06.164

44. X. Zhang, J. Qao, J. Zhao, D. Xu, F. Wang et al., Highefficiency electromagnetic wave absorption of cobalt decorated $\mathrm{NH}_{2}$-UIO-66-derived porous $\mathrm{ZrO}_{2} / \mathrm{C}$. ACS Appl. Mater. Interfaces. 11(39), 35959-35968 (2019). https://doi. org/10.1021/acsami.9b10168

45. W. Yang, X. Li, Y. Li, R. Zhu, H. Pang, Applications of metal-organic-framework-derived carbon materials. Adv. Mater. 31(6), 1804740 (2019). https://doi.org/10.1002/ adma. 201804740

46. W. Liu, L. Liu, Z. Yang, J. Xu, Y. Hou et al., A versatile route toward the electromagnetic functionalization of metal-organic framework-derived three-dimensional nanoporous carbon composites. ACS Appl. Mater. Interfaces. 10(10), 8965-8975 (2018). https://doi.org/10.1021/acsam i. 8 b00320

47. Q. Wu, H. Jin, W. Chen, S. Huo, X. Chen et al., Graphitized nitrogen-doped porous carbon composites derived from ZIF-8 as efficient microwave absorption materials. Mater. Res. Express 5(6), 065602 (2018). https://doi.org/10.1088/20531591/aac67e

48. F. Meng, H. Wang, F. Huang, Y. Guo, Z. Wang et al., Graphene-based microwave absorbing composites: a review and prospective. Compos. Part B Eng. 137, 260-277 (2018). https ://doi.org/10.1016/j.compositesb.2017.11.023

49. R. Shu, J. Zhang, C. Guo, Y. Wu, Z. Wan et al., Facile synthesis of nitrogen-doped reduced graphene oxide/nickel-zinc ferrite composites as high-performance microwave absorbers in the X-band. Chem. Eng. J. 384, 123266 (2020). https://doi. org/10.1016/j.cej.2019.123266

50. Y. Wu, R. Shu, X. Shan, J. Zhang, J. Shi et al., Facile design of cubic-like cerium oxide nanoparticles decorated reduced graphene oxide with enhanced microwave absorption properties. J. Alloys Compd. 817, 152766 (2020). https://doi. org/10.1016/j.jallcom.2019.152766

51. J. Yan, Y. Huang, C. Chen, X. Liu, H. Liu, The 3D CoNi alloy particles embedded in $\mathrm{N}$-doped porous carbon foams for high-performance microwave absorbers. Carbon 152, 545555 (2019). https://doi.org/10.1016/j.carbon.2019.06.064

52. Z. Wu, K. Tian, T. Huang, W. Hu, F. Xie et al., Hierarchically porous carbons derived from biomasses with excellent microwave absorption performance. ACS Appl. Mater. Interfaces. 10(13), 11108-11115 (2018). https://doi.org/10.1021/acsam i. 7 b 17264

53. N. Wu, C. Liu, D. Xu, J. Liu, W. Liu et al., Enhanced electromagnetic wave absorption of three-dimensional porous $\mathrm{Fe}_{3} \mathrm{O}_{4} / \mathrm{C}$ composite flowers. ACS Sustain. Chem. Eng. 6(9), 12471-12480 (2018). https://doi.org/10.1021/acssuschem eng.8b03097

54. M. Zeng, Q. Cao, J. Liu, B. Guo, X. Hao et al., Hierarchical cobalt selenides as highly efficient microwave absorbers with tunable frequency response. ACS Appl. Mater. Interfaces. 12(1), 1222-1231 (2020). https://doi.org/10.1021/acsam i. 9 b 15172
55. L.J. Yang, H.L. Lv, M. Li, Y. Zhang, J.C. Liu et al., Multiple polarization effect of shell evolution on hierarchical hollow $\mathrm{C} @ \mathrm{MnO}_{2}$ composites and their wideband electromagnetic wave absorption properties. Chem. Eng. J. 392, 10 (2020). https://doi.org/10.1016/j.cej.2019.123666

56. Z. Wang, R. Wei, J. Gu, H. Liu, C. Liu et al., Ultralight, highly compressible and fire-retardant graphene aerogel with self-adjustable electromagnetic wave absorption. Carbon 139, 1126-1135 (2018). https://doi.org/10.1016/j.carbo n.2018.08.014

57. K. Wang, Y. Chen, R. Tian, H. Li, Y. Zhou et al., Porous Co-C core-shell nanocomposites derived from Co-MOF-74 with enhanced electromagnetic wave absorption performance. ACS Appl. Mater. Interfaces. 10(13), 11333-11342 (2018). https://doi.org/10.1021/acsami.8b00965

58. R. Shu, G. Zhang, X. Wang, X. Gao, M. Wang et al., Fabrication of 3D net-like MWCNTs/ $/ \mathrm{ZnFe}_{2} \mathrm{O}_{4}$ hybrid composites as high-performance electromagnetic wave absorbers. Chem. Eng. J. 337, 242-255 (2018). https://doi.org/10.1016/j. cej.2017.12.106

59. Y. Zhang, Y. Huang, H. Chen, Z. Huang, Y. Yang et al., Composition and structure control of ultralight graphene foam for high-performance microwave absorption. Carbon 105, 438447 (2016). https://doi.org/10.1016/j.carbon.2016.04.070

60. J. Zhang, R. Shu, Y. Wu, Z. Wan, M. Zheng, Facile fabrication and enhanced microwave absorption properties of reduced graphene oxide/tin dioxide binary nanocomposites in the X-band. Synth. Met. 257, 116157 (2019). https://doi. org/10.1016/j.synthmet.2019.116157

61. Q. Song, F. Ye, L. Kong, Q. Shen, L. Han et al., Graphene and MXene nanomaterials: toward high-performance electromagnetic wave absorption in gigahertz band range. Adv. Funct. Mater. 30(31), 2000475 (2020). https://doi.org/10.1002/ adfm.202000475

62. G. Shao, J. Liang, W. Zhao, B. Zhao, W. Liu et al., Co decorated polymer-derived SiCN ceramic aerogel composites with ultrabroad microwave absorption performance. J. Alloys Compd. 813(15), 152007 (2020). https://doi.org/10.1016/j. jallcom.2019.152007

63. S. Dong, P. Hu, X. Li, C. Hong, X. Zhang et al., $\mathrm{NiCo}_{2} \mathrm{~S}_{4}$ nanosheets on $3 \mathrm{D}$ wood-derived carbon for microwave absorption. Chem. Eng. J. 398, 125588 (2020). https://doi. org/10.1016/j.cej.2020.125588

64. X. Wang, F. Pan, Z. Xiang, Q. Zeng, K. Pei et al., Magnetic vortex core-shell $\mathrm{Fe}_{3} \mathrm{O}_{4} @ \mathrm{C}$ nanorings with enhanced microwave absorption performance. Carbon 157, 130-139 (2020). https://doi.org/10.1016/j.carbon.2019.10.030

65. S. Dong, W. Zhang, X. Zhang, P. Hu, J. Han, Designable synthesis of core-shell SiCw@C heterostructures with thickness-dependent electromagnetic wave absorption between the whole X-band and Ku-band. Chem. Eng. J. 354, 767-776 (2018). https://doi.org/10.1016/j.cej.2018.08.062

66. L. Liu, S. Yang, H. Hu, T. Zhang, Y. Yuan et al., Lightweight and efficient microwave-absorbing materials based on loofahsponge-derived hierarchically porous carbons. ACS Sustain. 
Chem. Eng. 7(1), 1228-1238 (2019). https://doi.org/10.1021/ acssuschemeng.8b04907

67. H. Wang, F. Meng, F. Huang, C. Jing, Y. Li et al., Interface modulating CNTs@PANi hybrids by controlled unzipping of the walls of CNTs to achieve tunable high-performance microwave absorption. ACS Appl. Mater. Interfaces. 11(12), 12142-12153 (2019). https://doi.org/10.1021/acsami.9b011 22

68. J. Kuang, P. Jiang, F. Ran, W. Cao, Conductivity-dependent dielectric properties and microwave absorption of Al-doped SiC whiskers. J. Alloys Compd. 687, 227-231 (2016). https ://doi.org/10.1016/j.jallcom.2016.06.168

69. X. Qi, Y. Yang, W. Zhong, C. Qin, Y. Deng et al., Simultaneous synthesis of carbon nanobelts and carbon $/ \mathrm{Fe}-\mathrm{Cu}$ hybrids for microwave absorption. Carbon 48(12), 35123522 (2010). https://doi.org/10.1016/j.carbon.2010.05.047

70. H. Xu, X. Yin, X. Li, M. Li, S. Liang et al., Lightweight $\mathrm{Ti}_{2} \mathrm{CT}_{\mathrm{x}}$ MXene/Poly(vinyl alcohol) composite foams for electromagnetic wave shielding with absorption-dominated feature. ACS Appl. Mater. Interfaces. 11(10), 10198-10207 (2019). https://doi.org/10.1021/acsami.8b21671

71. C.G. Jayalakshmi, A. Inamdar, A. Anand, B. Kandasubramanian, Polymer matrix composites as broadband radar absorbing structures for stealth aircrafts. J. Appl. Polym. Sci. (2019). https://doi.org/10.1002/app.47241

72. J. Jiang, D. Li, D. Geng, J. An, J. He et al., Microwave absorption properties of core double-shell $\mathrm{FeCo} / \mathrm{C} / \mathrm{BaTiO}_{3}$ nanocomposites. Nanoscale 6(8), 3967-3971 (2014). https ://doi.org/10.1039/c3nr04087a

73. P. Liu, Y. Huang, J. Yan, Y. Zhao, Magnetic graphene@ PANI@ porous $\mathrm{TiO}_{2}$ ternary composites for high-performance electromagnetic wave absorption. J. Mater. Chem. C 4(26), 6362-6370 (2016). https://doi.org/10.1039/c6tc0 $1718 \mathrm{e}$

74. W. Duan, X. Yin, Q. Li, L. Schlier, P. Greil et al., A review of absorption properties in silicon-based polymer derived ceramics. J. Eur. Ceram. Soc. 36(15), 3681-3689 (2016). https://doi.org/10.1016/j.jeurceramsoc.2016.02.002

75. W. Zhou, R.-M. Yin, L. Long, H. Luo, W.-D. Hu et al., Enhanced high-temperature dielectric properties and microwave absorption of $\mathrm{SiC}$ nanofibers modified $\mathrm{Si}_{3} \mathrm{~N}_{4}$ ceramics within the gigahertz range. Ceram. Int. 44(11), 12301-12307 (2018). https://doi.org/10.1016/j.ceramint.2018.04.017

76. H. Lv, X. Liang, Y. Cheng, H. Zhang, D. Tang et al., Coin-like alpha- $\mathrm{Fe}_{2} \mathrm{O}_{3} @ \mathrm{CoFe}_{2} \mathrm{O}_{4}$ core-shell composites with excellent electromagnetic absorption performance. ACS Appl. Mater. Interfaces. 7(8), 4744-4750 (2015). https://doi.org/10.1021/ am508438s

77. B. Quan, X. Lang, G. Ji, J. Ma, P. Ouyang et al., Strong electromagnetic wave response derived from the construction of dielectric/magnetic media heterostructure and multiple interfaces. ACS Appl. Mater. Interfaces. 9(11), 9964-9974 (2017). https://doi.org/10.1021/acsami.6b15788

78. C. Zhou, X. Wang, H. Luo, L. Deng, S. Wang et al., Interfacial design of sandwich-like $\mathrm{CoFe} @ \mathrm{Ti}_{3} \mathrm{C}_{2} \mathrm{~T}_{\mathrm{x}}$ composites as high efficient microwave absorption materials. Appl. Surf.
Sci. 494, 540-550 (2019). https://doi.org/10.1016/j.apsus c. 2019.07 .208

79. N. Li, X. Xie, H. Lu, B. Fan, X. Wang et al., Novel twodimensional $\mathrm{Ti}_{3} \mathrm{C}_{2} \mathrm{~T}_{\mathrm{x}} / \mathrm{Ni}$-spheres hybrids with enhanced microwave absorption properties. Ceram. Int. 45(17), 2288022888 (2019). https://doi.org/10.1016/j.ceramint.2019.07.331

80. Z. Lou, C. Yuan, Y. Zhang, Y. Li, J. Cai et al., Synthesis of porous carbon matrix with inlaid $\mathrm{Fe}_{3} \mathrm{C} / \mathrm{Fe}_{3} \mathrm{O}_{4}$ micro-particles as an effective electromagnetic wave absorber from natural wood shavings. J. Alloys Compd. 775, 800-809 (2019). https ://doi.org/10.1016/j.jallcom.2018.10.213

81. T. Wu, Y. Liu, X. Zeng, T. Cui, Y. Zhao et al., Facile hydrothermal synthesis of $\mathrm{fe}_{3} \mathrm{O}_{4} / \mathrm{c}$ core-shell nanorings for efficient low-frequency microwave absorption. ACS Appl. Mater. Interfaces. 8(11), 7370-7380 (2016). https://doi.org/10.1021/ acsami.6b00264

82. M.A. Almessiere, Y. Slimani, H. Güngüneş, V.G. Kostishyn, S.V. Trukhanov et al., Impact of $\mathrm{Eu}^{3+}$ ion substitution on structural, magnetic and microwave traits of $\mathrm{Ni}-\mathrm{Cu}-\mathrm{Zn}$ spinel ferrites. Ceram. Int. (2020). https://doi.org/10.1016/j.ceram int.2020.01.132

83. D.S. Klygach, M.G. Vakhitov, D.A. Vinnik, A.V. Bezborodov, S.A. Gudkova et al., Measurement of permittivity and permeability of barium hexaferrite. J. Magn. Magn. Mater. 465, 290-294 (2018). https://doi.org/10.1016/j. jmmm.2018.05.054

84. D.A. Vinnik, D.S. Klygach, V.E. Zhivulin, A.I. Malkin, M.G. Vakhitov et al., Electromagnetic properties of BaFe12O19: Ti at centimeter wavelengths. J. Alloys Compd. 755, 177-183 (2018). https://doi.org/10.1016/j.jallcom.2018.04.315

85. A.V. Trukhanov, M.A. Almessiere, A. Baykal, S.V. Trukhanov, Y. Slimani et al., Influence of the charge ordering and quantum effects in heterovalent substituted hexaferrites on their microwave characteristics. J. Alloys Compd. 788, 11931202 (2019). https://doi.org/10.1016/j.jallcom.2019.02.303

86. L.Y. Matzui, A.V. Trukhanov, O.S. Yakovenko, L.L. Vovchenko, V.V. Zagorodnii et al., Functional magnetic composites based on hexaferrites: correlation of the composition. Magnetic and high-frequency properties. Nanomaterials 9(12), 1720 (2019). https://doi.org/10.3390/nano9121720

87. O.S. Yakovenko, L.Y. Matzui, L.L. Vovchenko, A.V. Trukhanov, I.S. Kazakevich et al., Magnetic anisotropy of the graphite nanoplatelet-epoxy and MWCNT-epoxy composites with aligned barium ferrite filler. J. Mater. Sci. 52(9), 53455358 (2017). https://doi.org/10.1007/s10853-017-0776-4

88. Y. Qing, D. Min, Y. Zhou, F. Luo, W. Zhou, Graphene nanosheet- and flake carbonyl iron particle-filled epoxysilicone composites as thin-thickness and wide-bandwidth microwave absorber. Carbon 86, 98-107 (2015). https://doi. org/10.1016/j.carbon.2015.01.002

89. O. Khani, M.Z. Shoushtari, K. Ackland, P. Stamenov, The structural, magnetic and microwave properties of spherical and flake shaped carbonyl iron particles as thin multilayer microwave absorbers. J. Magn. Magn. Mater. 428, 28-35 (2017). https://doi.org/10.1016/j.jmmm.2016.12.010 
90. S. Yan, C. Cao, J. He, L. He, Z. Qu, Investigation on the electromagnetic and broadband microwave absorption properties of $\mathrm{Ti}_{3} \mathrm{C}_{2}$ Mxene/flaky carbonyl iron composites. J. Mater. Sci.: Mater. Electron. 30(7), 6537-6543 (2019). https://doi. org/10.1007/s10854-019-00959-0

91. Q. Li, Z. Zhang, L. Qi, Q. Liao, Z. Kang et al., Toward the application of high frequency electromagnetic wave absorption by carbon nanostructures. Adv. Sci. (2019). https://doi. org/10.1002/advs.201801057

92. C. Fu, D. He, Y. Wang, X. Zhao, Enhanced microwave absorption performance of RGO-modified Co@C nanorods. Synth. Met. 257, 116187 (2019). https://doi.org/10.1016/j. synthmet.2019.116187

93. Y. Du, W. Liu, R. Qiang, Y. Wang, X. Han et al., Shell thickness-dependent microwave absorption of core-shell $\mathrm{Fe}_{3} \mathrm{O}_{4} @ \mathrm{C}$ composites. ACS Appl. Mater. Interfaces. 6(15), 12997-13006 (2014). https://doi.org/10.1021/am502910d

94. Y. Zhang, Y. Huang, T. Zhang, H. Chang, P. Xiao et al., Broadband and tunable high-performance microwave absorption of an ultralight and highly compressible graphene foam. Adv. Mater. 27(12), 2049-2053 (2015). https ://doi.org/10.1002/adma.201405788

95. H.-B. Zhao, J.-B. Cheng, J.-Y. Zhu, Y.-Z. Wang, Ultralight $\mathrm{CoNi} / \mathrm{rGO}$ aerogels toward excellent microwave absorption at ultrathin thickness. J. Mater. Chem. C 7(2), 441-448 (2019). https://doi.org/10.1039/c8tc05239e

96. H. Zhang, B. Wang, A. Feng, N. Zhang, Z. Jia et al., Mesoporous carbon hollow microspheres with tunable pore size and shell thickness as efficient electromagnetic wave absorbers. Compos. Part B Eng. 167, 690-699 (2019). https ://doi.org/10.1016/j.compositesb.2019.03.055

97. B. Wen, M.-S. Cao, Z.-L. Hou, W.-L. Song, L. Zhang et al., Temperature dependent microwave attenuation behavior for carbon-nanotube/silica composites. Carbon 65, 124-139 (2013). https://doi.org/10.1016/j.carbon.2013.07.110

98. B. Quan, W. Shi, S.J.H. Ong, X. Lu, P.L. Wang et al., Defect engineering in two common types of dielectric materials for electromagnetic absorption applications (Funct. Mater, Adv, 2019). https://doi.org/10.1002/adfm.201901236

99. H. Lv, H. Zhang, G. Ji, Z.J. Xu, Interface strategy to achieve tunable high frequency attenuation. ACS Appl. Mater. Interfaces. 8(10), 6529-6538 (2016). https://doi. org/10.1021/acsami.5b12662

100. G. Sun, B. Dong, M. Cao, B. Wei, C. Hu, Hierarchical dendrite-like magnetic materials of $\mathrm{Fe}_{3} \mathrm{O}_{4}$, gamma- $\mathrm{Fe}_{2} \mathrm{O}_{3}$, and $\mathrm{Fe}$ with high performance of microwave absorption. Chem. Mater. 23(6), 1587-1593 (2011). https://doi.org/10.1021/ $\mathrm{cm} 103441 \mathrm{u}$

101. M.-S. Cao, X.-X. Wang, M. Zhang, J.-C. Shu, W.-Q. Cao et al., Electromagnetic response and energy conversion for functions and devices in low-dimensional materials. Adv. Funct. Mater. 29(25), 1807398 (2019). https://doi. org/10.1002/adfm.201807398

102. X. Liang, B. Quan, Z. Man, B. Cao, N. Li et al., Self-assembly three-dimensional porous carbon networks for efficient dielectric attenuation. ACS Appl. Mater. Interfaces. 11(33),
30228-30233 (2019). https://doi.org/10.1021/acsami.9b083 65

103. Q. Liu, X. Liu, H. Feng, H. Shui, R. Yu, Metal organic framework-derived $\mathrm{Fe} /$ carbon porous composite with low Fe content for lightweight and highly efficient electromagnetic wave absorber. Chem. Eng. J. 314, 320-327 (2017). https://doi.org/10.1016/j.cej.2016.11.089

104. N. Li, G.-W. Huang, Y.-Q. Li, H.-M. Xiao, Q.-P. Feng et al., Enhanced microwave absorption performance of coated carbon nanotubes by optimizing the $\mathrm{Fe}_{3} \mathrm{O}_{4}$ nanocoating structure. ACS Appl. Mater. Interfaces. 9(3), 2973-2983 (2017). https://doi.org/10.1021/acsami.6b13142

105. Y. Cheng, J.Z.Y. Seow, H. Zhao, Z.J. Xu, G. Ji, A flexible and lightweight biomass-reinforced microwave absorber. Nano-Micro Lett. 12(1), 125 (2020). https://doi. org/10.1007/s40820-020-00461-x

106. Y. Yang, L. Xia, T. Zhang, B. Shi, L. Huang et al., $\mathrm{Fe}_{3} \mathrm{O}_{4} @$ LAS/RGO composites with a multiple transmission-absorption mechanism and enhanced electromagnetic wave absorption performance. Chem. Eng. J. 352, 510-518 (2018). https ://doi.org/10.1016/j.cej.2018.07.064

107. N. Zhang, Y. Huang, M. Zong, X. Ding, S. Li et al., Synthesis of $\mathrm{ZnS}$ quantum dots and $\mathrm{CoFe}_{2} \mathrm{O}_{4}$ nanoparticles co-loaded with graphene nanosheets as an efficient broad band EM wave absorber. Chem. Eng. J. 308, 214-221 (2017). https://doi. org/10.1016/j.cej.2016.09.065

108. H. Lv, Y. Guo, G. Wu, G. Ji, Y. Zhao et al., Interface polarization strategy to solve electromagnetic wave interference issue. ACS Appl. Mater. Interfaces. 9(6), 5660-5668 (2017). https ://doi.org/10.1021/acsami.6b16223

109. Y. Lin, J. Dai, H. Yang, L. Wang, F. Wang, Graphene multilayered sheets assembled by porous $\mathrm{Bi}_{2} \mathrm{Fe}_{4} \mathrm{O}_{9}$ microspheres and the excellent electromagnetic wave absorption properties. Chem. Eng. J. 334, 1740-1748 (2018). https://doi. org/10.1016/j.cej.2017.11.150

110. T. Hanai, Theory of the dielectric dispersion due to the interfacial polarization and its application to emulsions. KolloidZeitschrift 171(1), 23-31 (1960). https://doi.org/10.1007/ BF01520320

111. J.B. Goodenough, Summary of losses in magnetic materials. IEEE Trans. Magn. 38(5), 3398-3408 (2002). https://doi. org/10.1109/TMAG.2002.802741

112. M.-S. Cao, J.-C. Shu, X.-X. Wang, X. Wang, M. Zhang et al., Electronic structure and electromagnetic properties for 2D electromagnetic functional materials in gigahertz frequency. Ann. Phys. 531(4), 1800390 (2019). https://doi.org/10.1002/ andp. 201800390

113. B. Zhao, W. Zhao, G. Shao, B. Fan, R. Zhang, Morphologycontrol synthesis of a core-shell structured $\mathrm{NiCu}$ alloy with tunable electromagnetic-wave absorption capabilities. ACS Appl. Mater. Interfaces. 7(23), 12951-12960 (2015). https:// doi.org/10.1021/acsami.5b02716

114. J. Carrey, B. Mehdaoui, M. Respaud, Simple models for dynamic hysteresis loop calculations of magnetic singledomain nanoparticles: application to magnetic hyperthermia 
optimization. J. Appl. Phys. 109(8), 083921 (2011). https:// doi.org/10.1063/1.3551582

115. C.-L. Zhu, M.-L. Zhang, Y.-J. Qiao, G. Xiao, F. Zhang et al., $\mathrm{Fe}_{3} \mathrm{O}_{4} / \mathrm{TiO}_{2}$ core/shell nanotubes: synthesis and magnetic and electromagnetic wave absorption characteristics. J. Phys. Chem. C 114(39), 16229-16235 (2010). https://doi. org/10.1021/jp104445m

116. D. Xu, X. Xiong, P. Chen, Q. Yu, H. Chu et al., Superior corrosion-resistant 3D porous magnetic graphene foam-ferrite nanocomposite with tunable electromagnetic wave absorption properties. J. Magn. Magn. Mater. 469, 428-436 (2019). https ://doi.org/10.1016/j.jmmm.2018.09.019

117. X. Liang, Z. Man, B. Quan, J. Zheng, W. Gu et al., Environment-stable $\mathrm{Co}_{\mathrm{x}} \mathrm{Ni}_{\mathrm{y}}$ encapsulation in stacked porous carbon nanosheets for enhanced microwave absorption. Nano-Micro Lett. 12(1), 102 (2020). https://doi.org/10.1007/s40820-02000432-2

118. R. Shu, Y. Wu, Z. Li, J. Zhang, Z. Wan et al., Facile synthesis of cobalt-zinc ferrite microspheres decorated nitrogen-doped multi-walled carbon nanotubes hybrid composites with excellent microwave absorption in the X-band. Compos. Sci. Technol. 184, 107839 (2019). https://doi.org/10.1016/j.compscitec h.2019.107839

119. Z. Li, X. Li, Y. Zong, G. Tan, Y. Sun et al., Solvothermal synthesis of nitrogen-doped graphene decorated by superparamagnetic $\mathrm{Fe}_{3} \mathrm{O}_{4}$ nanoparticles and their applications as enhanced synergistic microwave absorbers. Carbon 115, 493502 (2017). https://doi.org/10.1016/j.carbon.2017.01.036

120. Y. Wu, R. Shu, J. Zhang, Z. Wan, J. Shi et al., Oxygen vacancies regulated microwave absorption properties of reduced graphene oxide/multi-walled carbon nanotubes/cerium oxide ternary nanocomposite. J. Alloys Compd. 819, 152944 (2020). https://doi.org/10.1016/j.jallcom.2019.152944

121. X. Zhao, Y. Wang, D.S. Li, X. Bu, P. Feng, Metal-organic frameworks for separation. Adv. Mater. (2018). https://doi. org/10.1002/adma.201705189

122. R. Zhao, Z. Liang, R. Zou, Q. Xu, Metal-organic frameworks for batteries. Joule 2(11), 2235-2259 (2018). https://doi. org/10.1016/j.joule.2018.09.019

123. Y. Lu, Y. Wang, H. Li, Y. Lin, Z. Jiang et al., MOF-derived porous $\mathrm{Co} / \mathrm{C}$ nanocomposites with excellent electromagnetic wave absorption properties. ACS Appl. Mater. Interfaces. 7(24), 13604-13611 (2015). https://doi.org/10.1021/acsam i. 5 b03177

124. J. Li, P. Miao, K.-J. Chen, J.-W. Cao, J. Liang et al., Highly effective electromagnetic wave absorbing prismatic $\mathrm{Co} / \mathrm{C}$ nanocomposites derived from cubic metal-organic framework. Compos. Part B Eng. 182, 107613 (2020). https://doi. org/10.1016/j.compositesb.2019.107613

125. B.-Y. Zhu, P. Miao, J. Kong, X.-L. Zhang, G.-Y. Wang et al., $\mathrm{Co} / \mathrm{C}$ composite derived from a newly constructed metalorganic framework for effective microwave absorption. Cryst. Growth Des. 19(3), 1518-1524 (2019). https://doi. org/10.1021/acs.cgd.9b00064

126. H. Wang, L. Xiang, W. Wei, J. An, J. He et al., Efficient and lightweight electromagnetic wave absorber derived from metal organic framework-encapsulated cobalt nanoparticles. ACS Appl. Mater. Interfaces. 9(48), 42102-42110 (2017). https://doi.org/10.1021/acsami.7b13796

127. R. Qiang, Y. Du, D. Chen, W. Ma, Y. Wang et al., Electromagnetic functionalized $\mathrm{Co} / \mathrm{C}$ composites by in situ pyrolysis of metal-organic frameworks (ZIF-67). J. Alloys Compd. 681, 384-393 (2016). https://doi.org/10.1016/j.jallc om.2016.04.225

128. K. Zhang, A. Xie, M. Sun, W. Jiang, F. Wu et al., Electromagnetic dissipation on the surface of metal organic framework (MOF)/reduced graphene oxide (RGO) hybrids. Mater. Chem. Phys. 199, 340-347 (2017). https://doi.org/10.1016/j. matchemphys.2017.07.026

129. H. Qiu, X. Zhu, P. Chen, S. Yang, X. Guo et al., Magnetic dodecahedral CoC-decoratedreduced graphene oxide as excellent electromagnetic wave absorber. J. Electron. Mater. 49(2), 1204-1214 (2020). https://doi.org/10.1007/ s11664-019-07837-9

130. J. Yuan, Q. Liu, S. Li, Y. Lu, S. Jin et al., Metal organic framework (MOF)-derived carbonaceous $\mathrm{Co}_{3} \mathrm{O}_{4} / \mathrm{Co}$ microframes anchored on RGO with enhanced electromagnetic wave absorption performances. Synth. Met. 228, 32-40 (2017). https://doi.org/10.1016/j.synthmet.2017.03.020

131. K. Zhang, F. Wu, J. Li, M. Sun, A. Xie et al., Networks constructed by metal organic frameworks (MOFs) and multiwall carbon nanotubes (MCNTs) for excellent electromagnetic waves absorption. Mater. Chem. Phys. 208, 198-206 (2018). https://doi.org/10.1016/j.matchemphy s.2018.01.008

132. Y. Yin, X. Liu, X. Wei, Y. Li, X. Nie et al., Magnetically aligned Co-C/MWCNTs composite derived from MWCNTinterconnected zeolitic imidazolate frameworks for a lightweight and highly efficient electromagnetic wave absorber. ACS Appl. Mater. Interfaces. 9(36), 30850-30861 (2017). https://doi.org/10.1021/acsami.7b10067

133. X. Xiao, W. Zhu, Z. Tan, W. Tian, Y. Guo et al., Ultrasmall Co/CNTs nanohybrid from metal organic framework with highly efficient microwave absorption. Compos. Part B Eng. 152, 316-323 (2018). https://doi.org/10.1016/j.compo sitesb.2018.08.109

134. S. Lu, Y. Meng, H. Wang, F. Wang, J. Yuan et al., Great enhancement of electromagnetic wave absorption of MWCNTs@ carbonaceous CoO composites derived from MWCNTs-interconnected zeolitic imidazole framework. Appl. Surf. Sci. 481, 99-107 (2019). https://doi.org/10.1016/j. apsusc.2019.03.018

135. H. Chen, R. Hong, Q. Liu, S. Li, F. Huang et al., CNFs@ carbonaceous $\mathrm{Co} / \mathrm{CoO}$ composite derived from CNFs penetrated through ZIF-67 for high-efficient electromagnetic wave absorption material. J. Alloys Compd. 752, 115-122 (2018). https://doi.org/10.1016/j.jallcom.2018.04.142

136. X. Sun, X. Lv, M. Sui, X. Weng, X. Li et al., Decorating $\mathrm{MOF}$-derived nanoporous $\mathrm{Co} / \mathrm{C}$ in chain-like polypyrrole (PPy) aerogel: a lightweight material with excellent electromagnetic absorption. Materials 11(5), 781-793 (2018). https://doi.org/10.3390/ma11050781 
137. X. Liu, L.-S. Wang, Y. Ma, Y. Qiu, Q. Xie et al., Facile synthesis and microwave absorption properties of yolk-shell $\mathrm{ZnO}-\mathrm{Ni}-\mathrm{C} / \mathrm{RGO}$ composite materials. Chem. Eng. J. 333, 92-100 (2018). https://doi.org/10.1016/j.cej.2017.09.139

138. S. Kang, W. Zhang, Z. Hu, J. Yu, Y. Wang et al., Porous core-shell zeolitic imidazolate framework-derived $\mathrm{Co} /$ NPC@ZnO-decorated reduced graphene oxide for lightweight and broadband electromagnetic wave absorber. J. Alloys Compd. 818, 152932 (2020). https://doi. org/10.1016/j.jallcom.2019.152932

139. C. Zhou, C. Wu, D. Liu, M. Yan, Metal-organic framework derived hierarchical $\mathrm{Co} / \mathrm{C} @ \mathrm{~V}_{2} \mathrm{O}_{3}$ hollow spheres as a thin, lightweight, and high-efficiency electromagnetic wave absorber. Chem. Eur. J. 25(9), 2234-2241 (2019). https:// doi.org/10.1002/chem.201805565

140. M. Liu, R. Tian, H. Chen, S. Li, F. Huang et al., One-dimensional chain-like $\mathrm{MnO} @ \mathrm{Co} / \mathrm{C}$ composites for high-efficient electromagnetic wave absorbent. J. Magn. Magn. Mater. 499, 166289 (2020). https://doi.org/10.1016/j.jmmm.2019.16628 9

141. R. Wang, M. He, Y. Zhou, S. Nie, Y. Wang et al., Metalorganic frameworks self-templated cubic hollow Co/N/C@ $\mathrm{MnO}_{2}$ composites for electromagnetic wave absorption. Carbon 156, 378-388 (2020). https://doi.org/10.1016/j.carbo n.2019.09.063

142. K. Zhang, F. Wu, A. Xie, M. Sun, W. Dong, In situ stringing of metal organic frameworks by $\mathrm{SiC}$ nanowires for high-performance electromagnetic radiation elimination. ACS Appl. Mater. Interfaces. 9(38), 33041-33048 (2017). https://doi. org/10.1021/acsami.7b11592

143. R. Shu, Z. Wan, J. Zhang, Y. Wu, Y. Liu et al., Facile design of three-dimensional nitrogen-doped reduced graphene oxide/multi-walled carbon nanotube composite foams as lightweight and highly efficient microwave absorbers. ACS Appl. Mater. Interfaces. 12(4), 4689-4698 (2020). https://doi. org/10.1021/acsami.9b16134

144. N. Yang, Z.-X. Luo, G.-R. Zhu, S.-C. Chen, X.-L. Wang et al., Ultralight three-dimensional hierarchical cobalt nanocrystals/N-doped CNTs/carbon sponge composites with a hollow skeleton toward superior microwave absorption. ACS Appl. Mater. Interfaces. 11(39), 35987-35998 (2019). https://doi.org/10.1021/acsami.9b11101

145. Z. Li, X. Han, Y. Ma, D. Liu, Y. Wang et al., MOFs-derived hollow $\mathrm{Co} / \mathrm{C}$ microspheres with enhanced microwave absorption performance. ACS Sustain. Chem. Eng. 6(7), 8904-8913 (2018). https://doi.org/10.1021/acssuschemeng.8b01270

146. Z. Zhang, Q. Zhu, X. Chen, Z. Wu, Y. He et al., Ni@C composites derived from Ni-based metal organic frameworks with a lightweight, ultrathin, broadband and highly efficient microwave absorbing properties. Appl. Phys. Express 12(1), 011001 (2019). https://doi.org/10.7567/1882-0786/aaeedc

147. B. Quan, G. Xu, H. Yi, Z. Yang, J. Xiang et al., Enhanced electromagnetic wave response of nickel nanoparticles encapsulated in nanoporous carbon. J. Alloys Compd. 769, 961968 (2018). https://doi.org/10.1016/j.jallcom.2018.08.069
148. Z. Yang, Y. Zhang, M. Li, L. Yang, J. Liu et al., Surface architecture of Ni-based metal organic framework hollow spheres for adjustable microwave absorption. ACS Appl. Nano Mater. 2(12), 7888-7897 (2019). https://doi.org/10.1021/acsan $\mathrm{m} .9 \mathrm{~b} 01881$

149. J. Yan, Y. Huang, Y. Yan, L. Ding, P. Liu, High-performance electromagnetic wave absorbers based on two kinds of nickel-based MOF-derived Ni@C microspheres. ACS Appl. Mater. Interfaces. 11(43), 40781-40792 (2019). https://doi. org/10.1021/acsami.9b12850

150. R. Yang, J. Yuan, C. Yu, K. Yan, Y. Fu et al., Efficient electromagnetic wave absorption by $\mathrm{SiC} / \mathrm{Ni} / \mathrm{NiO} / \mathrm{C}$ nanocomposites. J. Alloys Compd. 816, 152519 (2020). https://doi. org/10.1016/j.jallcom.2019.152519

151. X. Liang, B. Quan, Y. Sun, G. Ji, Y. Zhang et al., Multiple interfaces structure derived from metal-organic frameworks for excellent electromagnetic wave absorption. Part. Part. Syst. Char. 34(5), 1700006 (2017). https://doi.org/10.1002/ ppsc. 201700006

152. Z. Zhang, Y. Lv, X. Chen, Z. Wu, Y. He et al., Porous flowerlike Ni/C composites derived from MOFs toward highperformance electromagnetic wave absorption. J. Magn. Magn. Mater. 487, 165334 (2019). https://doi.org/10.1016/j. jmmm.2019.165334

153. R. Qiang, Y. Du, H. Zhao, Y. Wang, C. Tian et al., Metal organic framework-derived $\mathrm{Fe} / \mathrm{C}$ nanocubes toward efficient microwave absorption. J. Mater. Chem. A 3(25), 1342613434 (2015). https://doi.org/10.1039/C5TA01457C

154. S. Peng, S. Wang, G. Hao, C. Zhu, Y. Zhang et al., Preparation of magnetic flower-like carbon-matrix composites with efficient electromagnetic wave absorption properties by carbonization of MIL-101(Fe). J. Magn. Magn. Mater. 487, 165306 (2019). https://doi.org/10.1016/j.jmmm.2019.16530 6

155. P. Miao, R. Zhou, K. Chen, J. Liang, Q. Ban et al., Tunable Electromagnetic Wave Absorption Of Supramolecular Isomer-Derived Nanocomposites With Different Morphology. Adv. Mater. Interfaces 7(4), 1901820 (2020). https://doi. org/10.1002/admi.201901820

156. Y. Wang, W. Zhang, X. Wu, C. Luo, Q. Wang et al., Conducting polymer coated metal-organic framework nanoparticles: facile synthesis and enhanced electromagnetic absorption properties. Synth. Met. 228, 18-24 (2017). https://doi. org/10.1016/j.synthmet.2017.04.009

157. Z. Xiang, Y. Song, J. Xiong, Z. Pan, X. Wang et al., Enhanced electromagnetic wave absorption of nanoporous $\mathrm{Fe}_{3} \mathrm{O}_{4}$ @ carbon composites derived from metal-organic frameworks. Carbon 142, 20-31 (2019). https://doi.org/10.1016/j.carbo n. 2018.10 .014

158. X. Liang, B. Quan, G. Ji, W. Liu, H. Zhao et al., Tunable dielectric performance derived from the metal-organic framework/reduced graphene oxide hybrid with broadband absorption. ACS Sustain. Chem. Eng. 5(11), 10570-10579 (2017). https://doi.org/10.1021/acssuschemeng.7b02565

159. W. Gu, J. Lv, B. Quan, X. Liang, B. Zhang et al., Achieving $\mathrm{MOF}$-derived one-dimensional porous $\mathrm{ZnO} / \mathrm{C}$ nanofiber with 
lightweight and enhanced microwave response by an electrospinning method. J. Alloys Compd. 806, 983-991 (2019). https://doi.org/10.1016/j.jallcom.2019.07.334

160. Y. Jiao, J. Li, A. Xie, F. Wu, K. Zhang et al., Confined polymerization strategy to construct polypyrrole/zeolitic imidazolate frameworks (PPy/ZIFs) nanocomposites for tunable electrical conductivity and excellent electromagnetic absorption. Compos. Sci. Technol. 174, 232-240 (2019). https://doi. org/10.1016/j.compscitech.2019.03.003

161. J. Ma, W. Liu, X. Liang, B. Quan, Y. Cheng et al., Nanoporous $\mathrm{TiO}_{2} / \mathrm{C}$ composites synthesized from directly pyrolysis of a Ti-based MOFs MIL-125(Ti) for efficient microwave absorption. J. Alloys Compd. 728, 138-144 (2017). https:// doi.org/10.1016/j.jallcom.2017.08.274

162. L. Huang, C. Chen, X. Huang, S. Ruan, Y.-J. Zeng, Enhanced electromagnetic absorbing performance of MOFderived $\mathrm{Ni} / \mathrm{NiO} / \mathrm{Cu} @ \mathrm{C}$ composites. Compos. Part B Eng. 164, 583-589 (2019). https://doi.org/10.1016/j.composites b.2019.01.081

163. X. Zhang, J. Qiao, C. Liu, F. Wang, Y. Jiang et al., A MOFderived $\mathrm{ZrO}_{2} / \mathrm{C}$ nanocomposite for efficient electromagnetic wave absorption. Inorg. Chem. Front. 7(2), 385-393 (2020). https://doi.org/10.1039/c9qi01259a

164. J. Xiong, Z. Xiang, J. Zhao, L. Yu, E. Cui et al., Layered NiCo alloy nanoparticles/nanoporous carbon composites derived from bimetallic MOFs with enhanced electromagnetic wave absorption performance. Carbon 154, 391-401 (2019). https://doi.org/10.1016/j.carbon.2019.07.096

165. Y. Liu, Z. Chen, W. Xie, F. Qiu, Y. Zhang et al., Enhanced microwave absorption performance of porous and hollow CoNi@C microspheres with controlled component and morphology. J. Alloys Compd. 809, 151837 (2019). https://doi. org/10.1016/j.jallcom.2019.151837

166. C. Liu, J. Qiao, X. Zhang, D. Xu, N. Wu et al., Bimetallic MOF-derived porous $\mathrm{CoNi} / \mathrm{C}$ nanocomposites with ultrawide band microwave absorption properties. New J. Chem. 43(42), 16546-16554 (2019). https://doi.org/10.1039/c9nj0 $4115 \mathrm{j}$

167. D. Liu, R. Qiang, Y. Du, Y. Wang, C. Tian et al., Prussian blue analogues derived magnetic FeCo alloy/carbon composites with tunable chemical composition and enhanced microwave absorption. J. Colloid Interface Sci. 514, 10-20 (2018). https://doi.org/10.1016/j.jcis.2017.12.013

168. W. Liu, S. Tan, Z. Yang, G. Ji, Hollow graphite spheres embedded in porous amorphous carbon matrices as lightweight and low-frequency microwave absorbing material through modulating dielectric loss. Carbon 138, 143-153 (2018). https://doi.org/10.1016/j.carbon.2018.06.009

169. J. Ouyang, Z. He, Y. Zhang, H. Yang, Q. Zhao, Trimetallic FeCoNi@C nanocomposite hollow spheres derived from metal-organic frameworks with superior electromagnetic wave absorption ability. ACS Appl. Mater. Interfaces. 11(42), 39304-39314 (2019). https://doi.org/10.1021/acsami.9b114 30

170. F. Wang, N. Wang, X. Han, D. Liu, Y. Wang et al., Core-shell FeCo@carbon nanoparticles encapsulated in polydopamine-derived carbon nanocages for efficient microwave absorption. Carbon 145, 701-711 (2019). https://doi. org/10.1016/j.carbon.2019.01.082

171. L. Wang, B. Wen, X. Bai, C. Liu, H. Yang, NiCo alloy/carbon nanorods decorated with carbon nanotubes for microwave absorption. ACS Appl. Nano Mater. 2(12), 7827-7838 (2019). https://doi.org/10.1021/acsanm.9b01842

172. S. Wang, Y. Xu, R. Fu, H. Zhu, Q. Jiao et al., Rational construction of hierarchically porous $\mathrm{Fe}-\mathrm{Co} / \mathrm{N}$-doped carbon/ rGO composites for broadband microwave absorption. NanoMicro Lett. 11(1), 76 (2019). https://doi.org/10.1007/s4082 0-019-0307-8

173. X. Xu, F. Ran, H. Lai, Z. Cheng, T. Lv et al., In Situ confined bimetallic metal-organic framework derived nanostructure within 3D interconnected bamboo-like carbon nanotube networks for boosting electromagnetic wave absorbing performances. ACS Appl. Mater. Interfaces. 11(39), 35999-36009 (2019). https://doi.org/10.1021/acsami.9b14754

174. Y. Zhang, Z. Yang, M. Li, L. Yang, J. Liu et al., Heterostructured CoFe@C@ $\mathrm{MnO}_{2}$ nanocubes for efficient microwave absorption. Chem. Eng. J. 382, 123039 (2020). https://doi. org/10.1016/j.cej.2019.123039

175. R. Shu, W. Li, Y. Wu, J. Zhang, G. Zhang et al., Fabrication of nitrogen-doped cobalt oxide/cobalt/carbon nanocomposites derived from heterobimetallic zeolitic imidazolate frameworks with superior microwave absorption properties. Compos. Part B Engn. 178, 107518 (2019). https://doi. org/10.1016/j.compositesb.2019.107518

176. S. Wang, X. Ke, S. Zhong, Y. Lai, D. Qian, Y. Wang, Q. Wang, W. Jiang, Bimetallic zeolitic imidazolate frameworksderived porous carbon-based materials with efficient synergistic microwave absorption properties: the role of calcining temperature. RSC Adv. 7(73), 46436-46444 (2017). https:// doi.org/10.1039/c7ra08882e

177. X. Qi, J. Xu, Q. Hu, Y. Deng, R. Xie et al., Metal-free carbon nanotubes: synthesis, and enhanced intrinsic microwave absorption properties. Sci. Rep. 6, 28310-28310 (2016). https ://doi.org/10.1038/srep28310

178. C. Wang, X. Han, P. Xu, X. Zhang, Y. Du et al., The electromagnetic property of chemically reduced graphene oxide and its application as microwave absorbing material. Appl. Phys. Lett. 98(7), 072906 (2011). https://doi.org/10.1063/1.35554 36

179. H. Chen, Z. Huang, Y. Huang, Y. Zhang, Z. Ge et al., Synergistically assembled MWCNT/graphene foam with highly efficient microwave absorption in both $\mathrm{C}$ and $\mathrm{X}$ bands. Carbon 124, 506-514 (2017). https://doi.org/10.1016/j.carbo n.2017.09.007

180. S.K. Singh, M.J. Akhtar, K.K. Kar, Hierarchical carbon nanotube-coated carbon fiber: ultra lightweight, thin, and highly efficient microwave absorber. ACS Appl. Mater. Interfaces. 10(29), 24816-24828 (2018). https://doi.org/10.1021/acsam i. 8 b06673

181. A. Xie, F. Wu, M. Sun, X. Dai, Z. Xu et al., Self-assembled ultralight three-dimensional polypyrrole aerogel for effective 
electromagnetic absorption. Appl. Phys. Lett. 106(22), 222902 (2015). https://doi.org/10.1063/1.4921180

182. P. Zhang, X. Han, L. Kang, R. Qiang, W. Liu et al., Synthesis and characterization of polyaniline nanoparticles with enhanced microwave absorption. RSC Adv. 3(31), 1269412701 (2013). https://doi.org/10.1039/C3RA40973B

183. M. Cai, A. Shui, X. Wang, C. He, J. Qian et al., A facile fabrication and high-performance electromagnetic microwave absorption of $\mathrm{ZnO}$ nanoparticles. J. Alloys Compd. 842, 155638 (2020). https://doi.org/10.1016/j.jallcom.2020.155638

184. M. Green, Z. Liu, R. Smedley, H. Nawaz, X. Li et al., Graphitic carbon nitride nanosheets for microwave absorption. Mater. Today Phys. 5, 78-86 (2018). https://doi. org/10.1016/j.mtphys.2018.06.005
185. C. Liang, Z. Wang, L. Wu, X. Zhang, H. Wang et al., Light and strong hierarchical porous $\mathrm{SiC}$ foam for efficient electromagnetic interference shielding and thermal insulation at elevated temperatures. ACS Appl. Mater. Interfaces. 9(35), 29950-29957 (2017). https://doi.org/10.1021/acsami.7b07735

186. R.B. Yang, W.F. Liang, C.W. Lou, J.H. Lin, Electromagnetic and microwave absorption properties of magnetic stainless steel powder in 2-18 GHz. J. Appl. Phys. 111(7), 07A338 (2012). https://doi.org/10.1063/1.3693764

187. F. Wang, C. Long, T. Wu, W. Li, Z. Chen et al., Enhancement of low-frequency magnetic permeability and absorption by texturing flaky carbonyl iron particles. J. Alloys Compd. 823, 153827 (2020). https://doi.org/10.1016/j.jallcom.2020.153827 